\title{
Comparison of fission product release predictions using PARFUME with results from the AGR-1 safety tests
}

\author{
Blaise P. Collin, David A. Petti, Paul A. Demkowicz, John T. Maki \\ Idaho National Laboratory \\ 2525 Fremont Avenue, Idaho Falls, ID 83415, USA \\ Phone: +1-208-526-2217, blaise.collin@inl.gov
}

\begin{abstract}
Safety tests were conducted on fuel compacts from AGR-1, the first irradiation experiment of the Advanced Gas Reactor (AGR) Fuel Development and Qualification program, at temperatures ranging from 1600 to $1800^{\circ} \mathrm{C}$ to determine fission product release at temperatures that bound reactor accident conditions. The PARFUME (PARticle FUel ModEl) code was used to predict the release of fission products silver, cesium, strontium, and krypton from fuel compacts containing tristructural isotropic (TRISO) coated particles during fifteen of these safety tests. Comparisons between PARFUME predictions and post-irradiation examination results of the safety tests were conducted on two types of AGR-1 compacts: compacts containing only intact particles and compacts containing one or more particles whose SiC layers failed during safety testing. In both cases, PARFUME globally over-predicted the experimental release fractions by several orders of magnitude: more than three (intact) and two (failed SiC) orders of magnitude for silver, more than three and up to two orders of magnitude for strontium, and up to two and more than one orders of magnitude for krypton. The release of cesium from intact particles was also largely over-predicted (by up to five orders of magnitude) but its release from particles with failed $\mathrm{SiC}$ was only over-predicted by a factor of about three. These over-predictions can be largely attributed to an over-estimation of the diffusivities used in the modeling of fission product transport in TRISO-coated particles. The integral release nature of the data makes it difficult to estimate the individual over-estimations in the kernel or each coating layer. Nevertheless, a tentative assessment of correction factors to these diffusivities was performed to enable a better match between the modeling predictions and the safety testing results. The method could only be successfully applied to silver and cesium. In the case of strontium, correction factors could not be assessed because potential release during the safety tests could not be distinguished from matrix content released during irradiation. In the case of krypton, all the coating layers are partly retentive and the available data did not allow the level of retention in individual layers to be determined, hence preventing derivation of any correction factors.
\end{abstract}

\section{INTRODUCTION}

Model predictions were compared to experimental measurements of silver, cesium, strontium, and krypton release from fifteen tristructural isotropic (TRISO) fuel compacts that underwent safety testing following the first irradiation test of the Advanced Gas Reactor program (AGR-1). The safety tests on these compacts were conducted at both Oak Ridge National Laboratory (ORNL) and Idaho National Laboratory (INL) at isothermal temperatures of 1600,1700 , and $1800^{\circ} \mathrm{C}$. The results of these tests are presented in Ref. [1] and [2]. Ref. [3] presents the results of fuel performance modeling for the AGR-1 fuel during irradiation.

The modeling was performed using the particle fuel model computer code PARFUME (PARticle FUel ModEl) developed at INL. PARFUME is an advanced gas-cooled reactor fuel performance modeling and analysis code [4]. It has been developed as an integrated mechanistic code that evaluates the thermal, mechanical, and physico-chemical behavior of fuel particles during irradiation to determine the failure probability of a population of fuel particles given the particle-to-particle statistical variations in physical dimensions and material properties that arise from the fuel fabrication process, accounting for all viable mechanisms that can lead to 
particle failure. Specifically, PARFUME calculates the dimensional changes that affect the kernel (swelling) and coating layers (elastic, irradiation-induced shrinkage/swelling and creep, and thermal expansion) during irradiation. The subsequent stress levels are used to determine potential fracture of the coating layers and, ultimately, the probability of failure of the particle.

The code also determines the diffusion of fission products from the fuel through the particle coating layers, and through the fuel matrix to the coolant boundary. The subsequent release of fission products is calculated at the compact level (release of fission products from the compact) or particle level. The diffusivity of each layer can be individually set to a high value (typically $10^{-6} \mathrm{~m}^{2} / \mathrm{s}$ ) to simulate a failed layer with no capability of fission product retention.

PARFUME calculates the release fraction from a compact as the ratio of the number of atoms released from the compact to the amount produced in the compact fuel kernels and through uranium contamination. The release fraction obtained from safety tests was calculated by measuring the amount of fission products released from the compact and by normalizing that amount to a predicted compact source term obtained by as-run neutronics calculations of the AGR-1 experiment [5]. In this paper, this release fraction is simply referred to as "experimental" release fraction. Similarly, PARFUME can also calculate the release fraction of individual particles, which allows one to differentiate the contribution of intact or failed particles to the total compact release. In the comparison to experimental data from the safety tests, the predicted release fractions are calculated at the compact level, i.e., they are based on the amount of fission products released from the particles (intact or failed) and the compact matrix. In the case of silver, cesium, and krypton, the recommended diffusivities in the matrix are relatively high and PARFUME does not predict any fission product retention in the matrix during safety testing.

\section{AGR-1 SAFETY TESTING}

The Department of Energy (DOE) Advanced Gas Reactor Fuel Development and Qualification program was established to qualify TRISO fuel for use in High Temperature Gas Reactors (HTGRs). The primary goal of the program is to provide a baseline fuel qualification data set in support of the licensing and operation of an HTGR [6].

AGR-1 is the first of these irradiation tests. Irradiation began in the Advanced Test Reactor (ATR) at INL in December 2006 and completed in November 2009. A total of 72 compacts were irradiated in the AGR-1 experiment in six different capsules. The experiment completed 620 effective full power days (EFPDs) in the reactor and achieved calculated peak burnup of $19.6 \%$ fissions per initial heavy metal atom (FIMA) and fast neutron fluence of $4.30 \times 10^{25} \mathrm{n} / \mathrm{m}^{2}(\mathrm{E}>0.18 \mathrm{MeV})$ [7].

At completion of the irradiation, safety testing of selected irradiated compacts was conducted in the ORNL Core Conduction Cooldown Test Facility (CCCTF) and in the INL Fuel Accident Condition Simulator (FACS) furnace. A description of the two experimental systems has been provided previously $[8,9]$. The heating plans for isothermally-tested compacts consists of two temperature ramps of $120^{\circ} \mathrm{C} / \mathrm{hr}$ followed by temperature plateaus of 2 hours at $400^{\circ} \mathrm{C}$ and 12 hours at $1250^{\circ} \mathrm{C}$, respectively, and then a temperature ramp of $50^{\circ} \mathrm{C} / \mathrm{hr}$ until the maximum temperature $\left(1600,1700\right.$, or $\left.1800^{\circ} \mathrm{C}\right)$ is reached. A heating phase of nominally 300 hours follows at maximum temperature and then the compacts are brought back to room temperature $\left(30^{\circ} \mathrm{C}\right)$ with a ramp of $600^{\circ} \mathrm{C} / \mathrm{hr}$ [8]. The times used in these tests are much greater than calculated to occur in an actual modular HTGR, but they are typical of historic testing conducted during German TRISO fuel development. Table 1 lists the fifteen safety-tested compacts, while Figure 1 shows the safety test heating plans.

\section{PARFUME MODELING}

\subsection{AGR-1 Geometry and Fuel Characteristics}

The AGR-1 test train contains six capsules arranged vertically. Each AGR-1 capsule contains twelve fuel compacts arranged in three vertical stacks with each stack containing four compacts, as seen in Figure 2. Each compact is uniquely identified in the format $\mathrm{X}-\mathrm{Y}-\mathrm{Z}$, where $\mathrm{X}$ indicates the capsule, $\mathrm{Y}$ the axial level within the capsule, and $\mathrm{Z}$ the stack. The compacts in each capsule are held in a graphite holder with a diametral gap of about $0.1 \mathrm{~mm}$. 
AGR-1 compacts are right cylinders nominally $25.1 \mathrm{~mm}$ in length and $12.4 \mathrm{~mm}$ in diameter. Each compact contains $~ 4150$ fuel particles uniformly dispersed in a matrix composed of a thermosetting carbonaceous material. Each particle consists of a kernel composed of a heterogeneous mixture of uranium carbide and uranium dioxide (referred to as uranium oxycarbide or UCO; diameter $\sim 350 \mu \mathrm{m}$ ) coated with layers of porous carbon buffer $(\sim 100 \mu \mathrm{m})$, inner pyrolytic carbon (IPyC, $\sim 40 \mu \mathrm{m})$, silicon carbide (SiC, $\sim 35 \mu \mathrm{m}$ ), and outer pyrolytic carbon $(\mathrm{OPyC}, \sim 40 \mu \mathrm{m})$. AGR-1 fuel comprises a baseline fuel and three fuel variants, with each variant fabricated by varying the deposition parameters for either the IPyC or SiC layer, resulting in minor differences in properties for that layer. Detailed fuel characteristics of the AGR-1 fuel can be found in Ref. [10].

\subsection{Methodology and Input Parameters}

PARFUME is designed to evaluate fuel performance based on user inputs for fast neutron fluence and burnup with a corresponding set of thermal conditions. The neutronics and thermal conditions for all the compacts used for comparison to experimental measurements are based on results obtained from as-run neutronics calculations and as-run thermal analysis $[5,11]^{1}$. They are used for the boundary conditions of the irradiation phase. The other input parameters needed to model the AGR-1 irradiation and safety tests with PARFUME originate from the AGR-1 Irradiation Experiment Test Plan [10] for the fuel characteristics, particle geometry, compact characteristics, and material non-mechanical properties, and from a CEGA Corporation report [13] for the material mechanical properties.

PARFUME assumes that all particles in a compact experience similar irradiation and thermal histories over the course of irradiation. Practically, PARFUME models one particle using the average burnup and fast neutron fluence and the volume-average temperature of the whole compact. The thermal history evolves on a daily basis. For each compact, the daily temperatures of all the calculation nodes are averaged [11], and PARFUME uses the resulting volume-average compact daily temperatures to set the thermal history of the modeled TRISO particle. The daily temperatures are set as boundary conditions at the outer edge of the OPyC. From the OPyC boundary temperature, PARFUME calculates the temperature profile between the $\mathrm{OPyC}$ and the kernel center.

As noted in Ref. [3], the temperature is not uniform across a compact. The temperature spreads several hundred degrees between the cold side and the hot side of the compact, which leads to a significant range of fission product release from one particle to another during irradiation. Typically, TRISO particles on the cold side of the compact yield almost no release, while particles on the hot side have an enhanced release due to the exponential form of the Arrhenius law that dictates the calculated release. Therefore, the average release of all particles at their own temperature is larger than the release of an average particle at the volume-average temperature because the former release is mostly caused by the hotter particles. Consequently, using a volumeaverage temperature for the compact, instead of tracking the thousands of particles individually (which proves impractical), under-predicts the estimation of the release during irradiation. Since the amount of fission products released during safety testing depends on the amount released during irradiation, the assumption of a volumeaverage temperature during irradiation impacts the assessment of the fractional release during safety testing. Nevertheless, the impact is limited to less than $50 \%$ for silver and krypton and less than a factor of five for cesium and strontium, which is negligible compared to the orders of magnitude of over-prediction of the release of these fission products during safety testing (see Section 4).

Following the modeling of the irradiation phase, PARFUME models the heating phase using the designed heating plans (see Section 2). During safety testing, the burnup and fast neutron fluence do not evolve and they keep their end-of-irradiation values. Note that, including the modeling of the temperature ramps required to reach the safety test temperatures, $1600^{\circ} \mathrm{C}$ tests lasted 334 hours, $1700^{\circ} \mathrm{C}$ lasted 336 hours, and $1800^{\circ} \mathrm{C}$ test lasted 338 hours, all with 300-hour plateaus at their respective safety test temperatures. For purpose of comparison, experimental release fractions presented here were determined at these times. For safety tests whose duration was shorter than planned, PARFUME calculations were shortened accordingly to match experimental test duration.

The objective of the PARFUME calculations is to provide the estimated fractional release of fission product species $\mathrm{Ag}, \mathrm{Cs}, \mathrm{Sr}$, and $\mathrm{Kr}$ during the heating phase. The corresponding release fraction is defined as the amount of fission products released during the heating phase relative to the total inventory produced during irradiation.

\subsection{Fission Product Diffusion Model}

\footnotetext{
${ }^{1}$ The PARFUME calculations presented in this paper were computed prior to completion of post-irradiation examination (PIE), and they are based on an earlier version of the as-run neutronics calculations [12]. The difference between the burnup values in the two sets of calculations does not exceed a $1.2 \%$ relative deviation. Therefore, there is negligible impact on the calculated results of the irradiation phase.
} 
PARFUME models the transport of metallic fission products as a transient diffusion process described by Fick's laws of diffusion:

$$
\begin{aligned}
& \frac{\partial \mathrm{C}}{\partial \mathrm{t}}=-\nabla \mathrm{J}+\mathrm{S} \\
& \mathrm{J}=-\mathrm{D} \nabla \mathrm{C}
\end{aligned}
$$

where $\mathrm{C}$ is the atom concentration of the diffusing fission product $\left(\mathrm{at} / \mathrm{m}^{3}\right), \mathrm{J}$ is the diffusive atom flux $\left(\mathrm{at} / \mathrm{m}^{2}-\mathrm{s}\right), \mathrm{S}$ is the source (production rate) of atoms $\left(a t / \mathrm{m}^{3}-\mathrm{s}\right)$, and D is the atom diffusivity $\left(\mathrm{m}^{2} / \mathrm{s}\right)$.

The diffusion coefficients used for fission product transport are derived from the International Atomic Energy Agency (IAEA) Technical Document 978 [14] and displayed in Table 2. The corresponding diffusivities can be calculated using these diffusion coefficients in the following Arrhenius-type equation:

$\mathrm{D}=\mathrm{D}_{0,1} \mathrm{e}^{-\frac{\mathrm{Q}_{0,1}}{\mathrm{RT}}}+\mathrm{D}_{0,2} \mathrm{e}^{-\frac{\mathrm{Q}_{0,2}}{\mathrm{RT}}}$

where $\mathrm{D}_{0, \mathrm{i}}(\mathrm{i}=1$ or 2$)$ are pre-exponential factors $\left(\mathrm{m}^{2} / \mathrm{s}\right), \mathrm{Q}_{0, \mathrm{i}}$ are activation energies $(\mathrm{J} / \mathrm{mol}), \mathrm{R}$ is the universal gas constant $(8.3145 \mathrm{~J} / \mathrm{mol} / \mathrm{K})$, and $\mathrm{T}$ is the temperature $(\mathrm{K})$.

The transport of fission products in fuel particles is based on a model with five materials: kernel, buffer, $\mathrm{IPyC}, \mathrm{SiC}$, and OPyC. The fission products are assumed to flow without resistance through the buffer-IPyC gap that develops between the buffer and IPyC as the coating layers shrink under irradiation. Additionally, the calculations assume a non-flow condition at the TRISO particle center (due to spherical symmetry) and a fixed concentration of fission products on the OPyC outer surface. A net integrated flow of fission products is calculated as the release from TRISO particles and used as the source term for subsequent fuel compact transport analyses. The transport in fuel compacts is based on a model with two materials: the graphite containing fuel particles (compact matrix) and the surrounding un-fueled graphite (graphite holder of the AGR-1 capsules [10]). The thickness of the graphite holder is set to $1 \mu \mathrm{m}$ so the release of fission products can be obtained at the compact level. Again, a non-flow condition is assumed at the centerline of the fuel compact and a fixed concentration of fission products is set to zero on the outer surface of the graphite holder. The model assumes no gap between the compacts and the holders. Consequently, no sorption isotherms are used to model the transport of the fission products from the compacts to the graphite holders.

The modeling of fission product transport as Fickian diffusion is an approximation of a more complex transport process that, in particular, depends on the microstructure of the fuel materials and that may involve several mechanisms such as lattice diffusion, grain boundary diffusion, pore diffusion, nano-cracks, vapor transport, etc. Furthermore, effects like irradiation-induced trapping and adsorption, thermal decomposition of the coating layers, or chemical attack of these coating layers by other fission products such as palladium or rare earth elements potentially impact these transport mechanisms. These mechanisms are not accurately known and not explicitly modeled by PARFUME. Consequently, diffusion coefficients used in PARFUME are implicitly defined as "effective", implying that they describe the overall fission product transport using a simplified diffusion approach based on classical Fickian diffusion [15].

PARFUME can calculate fission product release at the compact or particle level [4]. The release from particles with failed layers can be obtained by setting the diffusivities in these layers to a value of $10^{-6} \mathrm{~m}^{2} / \mathrm{s}$. In these calculations, PARFUME models the fission product release from both intact particles and particles with both failed IPyC and SiC layers and calculates the subsequent release from the safety-tested compacts. The modeling assumes that the failure of the IPyC layer simultaneously triggers the failure of the SiC layer. The failures of the coating layers are assumed to occur at the start of the heating test. The results are then compared to the measured release data.

\section{FISSION PRODUCT RELEASE}

As mentioned in Section 3.3, fission product release is modeled from both intact particles and particles with both failed IPyC and SiC layers within a compact. Specifically, two sets of calculations were performed with PARFUME: the first set calculated the diffusive release from an intact particle, while the second set calculated the diffusive release from a particle with failed IPyC and SiC layers and intact OPyC layer. Based on PIE measurements after the safety tests [16], the number of particles whose SiC layers failed during safety testing was 
estimated and reported in Table 3. The numbers in Table 3 were then used to combine the two sets of calculations accordingly and, therefore, to model the release from compacts containing only intact particles or containing particles with failed SiC layers. The subsequent calculated compact release was then compared to the release data.

Experimental data were obtained for Ag-110m, Cs-134, Sr-90, and Kr-85. PARFUME does not distinguish between isotopes but the calculation of the release fraction is independent of the isotope provided that all isotopes of a given species have the same diffusion behavior, which is assumed in these comparisons.

\subsection{Silver Release}

Post-irradiation deconsolidation-leach-burn-leach (DLBL) of select AGR-1 irradiated compacts has revealed non-negligible silver retention in the matrix, with retention levels from $\sim 3.3 \times 10^{-3}$ to $\sim 1.2 \times 10^{-1}$ of the total silver inventory [17]. Safety testing data showed a prompt release of silver during the initial phase of the tests, roughly corresponding to the temperature ramp steps and first 24 hours spent at the isothermal test temperature. The corresponding levels of silver release during this initial phase ranged from $\sim 2.9 \times 10^{-3}$ to $\sim 3.4 \times 10^{-1}$ for the fifteen tested compacts, representing from 44 to more than $99 \%$ of the total observed release during the entire safety tests. Therefore, this promptly released silver is believed to be silver retained in the matrix, or possibly in the OPyC layer, at the end of the irradiation phase, and which was then quickly driven out of the compact at the elevated temperatures experienced during the tests [1]. For the purposes of the comparisons presented here, it was assumed that the silver released during the ramp steps and during approximately the first 24 hours at the test temperature was due primarily to inventory retained in the compact outside of intact $\mathrm{SiC}$ at the end of irradiation. Conversely, the fractional release from intact particles during the heating phase is approximated by considering only the amount of silver released from the compacts after the first $\sim 24$ hours spent at the safety test temperature. The corresponding release fractions are referred to as "matrix-corrected release fractions" to distinguish them from the values without any correction obtained by the actual measurements and presented in AGR-1 safety test publications. These corrected release fractions are an attempt at removing the contribution from silver remaining in the matrix (or $\mathrm{OPyC}$ ) at the end of irradiation. In addition, post-irradiation comparisons between PARFUME and experimental AGR-1 data showed that silver matrix retention is much higher than predicted [3]. Indeed, PARFUME predicts negligible retention of silver during irradiation because of its relatively high diffusivity in the matrix. For all fifteen compacts, the calculated silver retained fraction in the matrix at the end of irradiation is less than $0.1 \%$, up to two orders of magnitude lower than the maximum observed prompt silver release. Consequently, correcting the experimental silver release from its assumed matrix content allows a more consistent comparison between experimental data and model predictions. Nevertheless, if the predicted silver release during safety testing is exclusively from the particles, it is not possible from the experimental data to discriminate between silver released from the particles or slowly driven out of the matrix during the safety tests. Therefore, the over-prediction of silver release could be under-estimated if some of the released silver is from the matrix and not the particles.

Figures 3 and 4 show the matrix-corrected release fractions of silver from compacts containing only intact particles and from compacts containing particles with failed SiC layers, respectively. They only include the release measured after the first $\sim 24$ hours spent at the safety test temperature. PARFUME calculations also exclude the silver that is predicted to be left outside of the SiC layer but inside the compact at the end of irradiation. This fraction was easily obtained by imposing a very low diffusivity in SiC in a dummy calculation so that the calculated silver release fraction only corresponds to silver calculated to reside in the OPyC layer or matrix at the end of irradiation. This fraction was then subtracted from the release fraction calculated for the safety test. The subsequent result represents the calculated fraction of silver that is predicted to be released from the kernel and/or through the $\mathrm{SiC}$ layer during safety testing. Compacts 3-2-2 and 3-3-2 are excluded from these plots because of unplanned temperature cycles at the beginning of their respective safety tests that caused some silver release which is believed to be from intact particles, and not from silver outside the $\mathrm{SiC}$ at the end of irradiation. This phenomenon is discussed further in Ref. [1] and [2].

Comparison of safety testing data between Figures 3 and 4 shows that the release is associated with intact particles: the measured release from compacts containing particles with failed SiC (Figure 4) is similar to the release from compacts containing only intact particles (Figure 3), when data at similar temperatures (1600 and $1700^{\circ} \mathrm{C}$ ) are compared. Because of the high release from intact particles, silver release from particles with failed $\mathrm{SiC}$ cannot be discerned. 
Figures 3 and 4 show a large over-prediction of the release from compacts containing only intact particles and from compacts containing particles with failed SiC layers, respectively. The over-predicted release is either from (Figure 3) or largely dominated by (Figure 4) intact particles and, therefore, the over-predictions are associated with an over-estimation of the diffusivity of silver in SiC. The potential over-estimation of the diffusivity in the kernel cannot be assessed. Although the calculated and experimental release fractions during the safety tests are impacted by the amount of silver released during irradiation (predicted and experimental, respectively), Ref. [3] showed a reasonably good agreement between these predicted and experimental silver release fractions for AGR1 compacts during the irradiation phase. Consequently, the discrepancies between the experimental and predicted results observed in Figures 3 and 4 are not attributed to the irradiation phase but they are rather assumed to be solely caused by an over-estimation of the diffusivity of silver in SiC at the safety test temperatures.

Figure 5 shows the impact of a reduction in the diffusivity of silver in $\mathrm{SiC}$ on the calculated matrix-corrected release fractions from intact particles at 1600,1700 , and $1800^{\circ} \mathrm{C}$ at the end of the safety tests. The IAEA diffusivity was divided by successive powers of ten and the subsequent release fractions were calculated at these three safety test temperatures and displayed in Figure 5 for select Compacts 6-4-1 and 5-3-3 (1600 $\left.{ }^{\circ} \mathrm{C}\right)$, Compacts 3-3-1 and 4-4-3 $\left(1700^{\circ} \mathrm{C}\right)$, and Compacts 3-2-3 and 4-4-1 (1800 $\left.{ }^{\circ} \mathrm{C}\right)$. Compacts 6-4-1, 3-3-1, and 3-2-3 exhibit the highest discrepancies between PARFUME and experimental matrix-corrected release fractions among all compacts tested at their respective temperatures. Compacts 5-3-3, 4-4-3, and 4-4-1 have the highest experimental matrix-corrected release fractions at their respective temperatures. As the diffusivity decreases and less silver can diffuse through the $\mathrm{SiC}$ layer, the calculated release fraction tends towards zero. Also shown on the plots are the corresponding experimental matrix-corrected release fractions of the six compacts (dashed lines). The intersection of the curves of the diffusivity-dependent release fraction with the experimental release fraction provides an estimate of how much the diffusivity in $\mathrm{SiC}$ needs to be corrected for the calculated release fraction to match the experimental release fraction. Correction factors to the PARFUME diffusivities are introduced to estimate the magnitude of their over-prediction. They are defined as:

$\mathrm{D}_{\mathrm{c}}=\mathrm{F} \times \mathrm{D}_{\mathrm{m}} \quad$ (eq. 4$)$

where $\mathrm{D}_{c}$ is the corrected diffusivity, $\mathrm{D}_{\mathrm{m}}$ is the original diffusivity used in the modeling (see Table 2), and $\mathrm{F}$ is the correction factor. When $\mathrm{F}<1$, smaller correction factors are indicative of original diffusivities that are more largely over-predicted. For each compact, a set of decreasing diffusivities and corresponding calculated release fractions was obtained, as illustrated for the three compacts in Figure 5. The correction factor for a given compact was calculated by regression analysis on this data set, i.e., by looking for the decreased diffusivity that would lead to a calculated release fraction equal to the experimental release fraction.

Table 4 summarizes the values of the correction factor to the diffusivity of silver in SiC for thirteen heating tests at 1600,1700 , and $1800^{\circ} \mathrm{C}$. Compacts 3-2-2 and 3-3-2 were again excluded from the analysis. The correction factors range from $2 \times 10^{-4}$ to $4 \times 10^{-3}$ at $1600^{\circ} \mathrm{C}$, from $8 \times 10^{-4}$ to $2 \times 10^{-3}$ at $1700^{\circ} \mathrm{C}$, and from $2 \times 10^{-3}$ to $4 \times 10^{-2}$ at $1800^{\circ} \mathrm{C}$. Compact 6-4-3 has the lowest experimental matrix-corrected release fraction and requires the largest reduction of the silver diffusivity in $\mathrm{SiC}$ (i.e., smallest correction factor: $2 \times 10^{-4}$ ) to adjust PARFUME over-predictions to match the corresponding experimental release fraction. Conversely, Compacts 4-3-2 and 4-41 have the highest experimental matrix-corrected release fractions and, therefore, require the smallest reduction of the silver diffusivity in $\mathrm{SiC}$ (i.e., largest correction factors: $3 \times 10^{-2}$ and $4 \times 10^{-2}$, respectively). Although the discrepancies in the calculated correction factors at each temperature prevent the derivation of accurate average values, it can be concluded that the diffusivity of silver in $\mathrm{SiC}$ is over-estimated by a factor of around 1,000 at 1600 and $1700^{\circ} \mathrm{C}$, and 100 at $1800^{\circ} \mathrm{C}$.

These correction factors would be significantly larger should the release fractions not be corrected from matrix content. They would range from $6 \times 10^{-3}$ to $7 \times 10^{-1}$ at $1600^{\circ} \mathrm{C}$, from $3 \times 10^{-2}$ to $1 \times 10^{-1}$ at $1700^{\circ} \mathrm{C}$, and from $1 \times 10^{-2}$ to $8 \times 10^{-2}$ at $1800^{\circ} \mathrm{C}$. Overall, the correction factors would be up to two orders of magnitude larger without any matrix content correction. This stems from the fact that the experimental matrix content represents a large fraction of the total observed silver release during the safety tests, whereas the calculated matrix content is negligible compared to the predicted total silver release. One major result of this observation is that the matrix is far more retentive of silver than expected from IAEA data. It is not clear whether this higher retention is due to an over-prediction of the diffusivity of silver in the matrix or to sorption/desorption effects at the surface of the compacts and graphite holders that are not modeled in PARFUME.

\subsection{Cesium Release}


As suggested by Ref. [3], the diffusivity of cesium in the kernel during irradiation might be over-estimated by PARFUME by a factor of 25 to 250, while the diffusivity in SiC should be reduced by 20 to $60 \%$ to better match experimental data. To conduct more accurate comparisons of cesium release during safety testing between PARFUME and experimental results, best-estimate correction factors of $1.25 \times 10^{-2}\left(\approx(25 \times 250)^{-1 / 2}\right)$ and $0.6(\approx$ $\left.(0.4 \times 0.8)^{1 / 2}\right)$ were applied in PARFUME to the diffusivities of cesium in the kernel and in SiC, respectively, during the irradiation phase.

As is the case for silver release, safety testing data showed a prompt release of cesium during the initial phase of the tests. In the case of compacts containing only intact particles, this prompt release is of the order of magnitude of the matrix content measured by post-irradiation DLBL [17]. It ranges from $2 \times 10^{-7}$ to $3 \times 10^{-6}$ for the five compacts tested at $1600^{\circ} \mathrm{C}$ and containing only intact particles and represents 30 to $50 \%$ of the total release from these compacts during the safety tests. Therefore, this prompt release was assumed to come from the matrix and the experimental and predicted release fractions were corrected accordingly the same way it was done for silver. The predicted matrix content ranges from $1 \times 10^{-8}$ to $2 \times 10^{-6}$ for these five compacts which is at least three orders of magnitude lower than their predicted release fractions at the end of the safety tests. On the other hand, in the case of compacts containing particles with failed $\mathrm{SiC}$ at the start of the test (or particles in which the $\mathrm{SiC}$ layer failed very early in the test), the prompt release was much larger and it is believed to include cesium released by the kernels of these particles with failed $\mathrm{SiC}$ layers, and it is not possible to discriminate the minor fraction coming from the matrix.

Figures 6 and 7 compare the resulting calculated and experimental cesium release fractions for compacts containing only intact particles and compacts containing particles with failed SiC layers, respectively. Figure 6 shows that the measured release from intact particles is limited. Moreover, it is over-predicted by PARFUME by more than three orders of magnitude. The large over-prediction likely means an over-estimation of the diffusivity of cesium in $\mathrm{SiC}$ at the safety test temperatures, in addition to the over-estimation during irradiation. For compacts containing particles with failed SiC, Figure 7 shows a fairly good agreement between safety testing data and PARFUME, when considering no release from the intact particles in the PARFUME predictions, with an over-prediction by a factor of three at most. This may indicate that the diffusivity in the kernel is somewhat overestimated in PARFUME, or that there could be other mechanisms of cesium retention within a particle that are not accounted for in the model. For the purposes of the present comparison between experimental data and PARFUME predictions, the deviation is assumed to be due to an over-estimation of the diffusivity of cesium in the kernel in PARFUME. Since the PyC layers are non-retentive to cesium at these high temperatures and because a failed $\mathrm{SiC}$ layer is assumed to also be non-retentive, the release from a particle with failed $\mathrm{SiC}$ is controlled, in the model, by the diffusivity in the kernel. In that regard, the effective diffusivity of cesium in $\mathrm{UO}_{2}$ used in the PARFUME modeling appears too high to explain the observed cesium release from the UCO kernels. Although cesium might be more mobile in UCO than in $\mathrm{UO}_{2}$ [19] other mechanisms might slow down its transport. As a net result, the effective diffusivity of cesium in UCO that encompasses all these mechanisms in the simplified approach of Fickian diffusion should be reduced compared to its $\mathrm{UO}_{2}$ counterpart. Additionally, because of the respective magnitude of the experimental release fractions in Figure $6\left(<10^{-5}\right)$ and in Figure 7 $\left(>10^{-4}\right)$, the release from compacts containing particles with failed $\mathrm{SiC}$ can be mostly attributed to the particles rather than the matrix.

Using the best-estimate irradiation correction factors, Figures 8 and 9 show the fractional release of cesium as a function of time for two compacts, one containing only intact particles (Compact 5-3-3 tested at $1600^{\circ} \mathrm{C}$ ) and one containing particles with failed $\mathrm{SiC}$ (Compact 3-2-3 tested at $1800^{\circ} \mathrm{C}$ ). The cesium matrix content was not corrected in Figure 8 to show the prompt release early in the test, but the total release during this test was corrected assuming that the early release was from the matrix (as discussed above) when comparing with the PARFUME calculations. For Compact 5-3-3, the matrix content accounts for half of the measured release. In the case of PARFUME, the matrix content is $\sim 10^{-7}$. Figure 8 demonstrates the over-prediction of cesium release by PARFUME. This over-prediction is also noticeable in the constantly increasing calculated fractional release, whereas the experimental fractional release is somewhat flat after the initial prompt release. This means that the predicted diffusion of cesium through the $\mathrm{SiC}$ layer is too large, as experimental measurements show a very small release rate of cesium. The prompt release of cesium from Compact 3-2-3 predicted by PARFUME is the result of the modeling of $\mathrm{SiC}$ failures from the start of the test (see Section 3.3) as cesium is not held up in the particle and is being released very rapidly. In the case of Compact 3-2-3, experimental measurements show a slow diffusive release, which is believed to be indicative of the successive failures of SiC layers in the estimated eleven particles that experienced $\mathrm{SiC}$ failure during this test (see Table 3) as discussed in Ref. [1]. 
The comparison between PARFUME and experimental release fractions from compacts containing particles with failed SiC layers shown in Figure 7 suggests an overall over-prediction by PARFUME. Assuming that this over-prediction is caused by an over-estimation of the diffusivity of cesium in the kernel, Figure 10 shows the impact of a decrease of this diffusivity on the calculated release fractions from particles with failed $\mathrm{SiC}$ for select Compacts 6-4-1 $\left(1600^{\circ} \mathrm{C}\right), 5-1-1\left(1700^{\circ} \mathrm{C}\right)$, and $5-1-3\left(1800^{\circ} \mathrm{C}\right)$ at the end of their respective safety tests. As the diffusivity in the kernel decreases, the release fraction tends towards an asymptotic value, which corresponds to the fraction released by the kernel that is left in the coating layers and matrix at the end of irradiation. This cesium is subsequently released during the safety tests but its calculated fractional release is not impacted by the magnitude of the diffusivity in the kernel since it is already outside of the kernel at the beginning of safety testing. Consequently, the asymptotic release fraction represents the calculated minimum release fraction from a particle with failed SiC during safety testing, i.e., assuming no additional release from the kernel during the safety test and full release of the cesium not held up in the kernel through the failed IPyC and $\mathrm{SiC}$ layers, intact OPyC layer, and matrix. Also shown on the plots (dashed lines) are the target release fractions that the particles with failed $\mathrm{SiC}$ should have to produce the observed experimental compact release, assuming the release is controlled by the diffusivity in the kernel only. Considering PARFUME predicts $~ 100 \%$ cesium release from particles with failed $\mathrm{SiC}$, these target values are simply obtained by dividing the experimental compact release fractions by their calculated ones (it is assumed that all particles with failed $\mathrm{SiC}$ within a given compact yield the same cesium release and that intact particles do not contribute to cesium release). Indeed, excluding the release from intact particles, the predicted release fraction from a compact containing particles with failed $\mathrm{SiC}$ is obtained by multiplying the number of such particles (see Table 3 ) by their individual release fraction ( 100\%) and dividing by the total number of particles in the compact $(\sim 4150)$. Therefore, matching experimental release fractions requires lowering the individual release fraction from $\sim 100 \%$ to these target values. The intersection of the curve of the diffusivity-dependent release fraction with the target release fraction provides an estimate of how much the diffusivity in the kernel needs to be corrected during the safety test for the calculated compact release fraction to match the experimental release fraction. As seen in Figure 10, a kernel diffusivity correction factor of about $4 \times 10^{-3}$ would allow the calculated release fraction of Compact 6-4-1 to closely match the experimental release fraction, while correction factors of $7 \times 10^{-4}$ and $2 \times 10^{-3}$ would give a match for Compact 5-1-1 and Compact 5-13 , respectively.

Table 5 lists the nine compacts containing particles with failed SiC tested at safety test temperatures of 1600, 1700 , and $1800^{\circ} \mathrm{C}$. Table 5 shows the cesium release fractions from the compacts calculated by PARFUME and derived from experimental measurements, as well as the target release fractions from particles with failed $\mathrm{SiC}$ that would lead to the total release fractions observed from each compact. Table 5 also shows the calculated minimum release fractions during safety testing which, in the model, represent the inventory that was mostly retained by the $\mathrm{SiC}$ layer during irradiation and promptly released from particles with failed $\mathrm{SiC}$ during the safety tests. These values are indicated by the asymptote reached by the curves in Figure 10, when the correction factor is decreased to the lowest values. Finally, Table 5 shows the correction factors to the diffusivity of cesium in the kernel allowing PARFUME predictions to match experimental release fractions. The correction factors range from $4 \times 10^{-3}$ to $4 \times 10^{-2}$ at $1600^{\circ} \mathrm{C}$, from $1 \times 10^{-4}$ to $7 \times 10^{-4}$ at $1700^{\circ} \mathrm{C}$, and from $1 \times 10^{-3}$ to $3 \times 10^{-3}$ at $1800^{\circ} \mathrm{C}$. Compact 4-3-2 has no correction factor since the initial predicted release fraction is lower than the experimental one.

Figure 6 shows a large over-prediction by PARFUME of the release fractions of cesium for compacts containing only intact particles. This over-prediction is assumed to be mostly caused by an over-estimation of the diffusivity of cesium in $\mathrm{SiC}$ at $1600^{\circ} \mathrm{C}$. To determine the correction factors to this diffusivity that are required for PARFUME predictions to match experimental results, the over-estimation of the diffusivity of cesium in the kernel during safety testing must be taken into account, in addition to the irradiation correction factors previously mentioned. From the safety test correction factors in Table 5, a best-estimate value of $1.25 \times 10^{-2}$ can be derived for the correction factor to the diffusivity in the kernel at $1600^{\circ} \mathrm{C}$. Table 6 lists the five compacts containing only intact particles tested at $1600^{\circ} \mathrm{C}$ and the correction factors to the diffusivity of cesium in $\mathrm{SiC}$ allowing PARFUME predictions to match experimental release fractions. The correction factors range from $5 \times 10^{-3}$ to $6 \times 10^{-2}$. They would range from $7 \times 10^{-3}$ to $1 \times 10^{-1}$ without any matrix content correction on the experimental and predicted release fractions. Since compacts that were safety tested at 1700 or $1800^{\circ} \mathrm{C}$ do not only contain intact particles, no correction factors could be derived at these temperatures.

\subsection{Strontium Release}

Figures 11 and 12 show the fractional release of strontium for compacts containing only intact particles and compacts containing particles with failed $\mathrm{SiC}$ layers, respectively. Comparison of safety testing data between 
Figures 11 and 12 shows that, overall, the release is dominated by intact particles. Release fractions of compacts containing particles with failed SiC (Figure 12) are similar to release fractions of compacts containing only intact particles (Figure 11), when data at similar temperatures $\left(1600\right.$ and $\left.1700^{\circ} \mathrm{C}\right)$ are compared. Because of the dominant release from intact particles, strontium release from particles with failed SiC cannot be discerned.

It is not possible to determine directly if the strontium release measured during safety testing is due to release through intact $\mathrm{SiC}$ or simply from residual inventory outside the $\mathrm{SiC}$ at the end of irradiation. The total inventory of strontium release from the compacts during safety tests at $1600^{\circ} \mathrm{C}$ is similar to the levels found in as-irradiated compacts outside of the $\mathrm{SiC}$ layer [17]. At the end of the safety tests, the amount of strontium outside the $\mathrm{SiC}$ is not negligible compared to the amount collected on the deposition cups in the furnace [1]. Therefore, it is not clear whether any of the strontium released during safety testing is from intact particles, if it simply results from slow release from strontium already outside of the $\mathrm{SiC}$ at the end of irradiation, or a combination of both. However, the bulk of experimental data suggests that the majority of the strontium release from safety testing is due to inventory residing outside of $\mathrm{SiC}$ at the end of irradiation [1].

Figures 11 and 12 show a large over-prediction of the release from compacts containing only intact particles and from compacts containing particles with failed SiC layers by up to more than three and more than two orders of magnitude, respectively. The over-prediction might be even larger if the measured release does not originate from the particles.

Figures 13 and 14 show the fractional release of strontium as a function of time for Compact 5-3-3 and Compact 3-2-3. The figures demonstrate the over-prediction of strontium release by PARFUME. The prompt release of strontium from Compact 3-2-3 predicted by PARFUME is again the result of the modeling of SiC failures from the start of the test, but it is less rapid than for cesium (see Figure 9) because the kernel acts as a retentive barrier to strontium diffusion.

Part of the over-prediction may be attributed to the irradiation phase. Indeed, comparisons between PIE and PARFUME on strontium release at the end of irradiation showed that the diffusivity of strontium is overestimated in either the kernel or in the SiC layer, or possibly in both, but the available data do not allow for a precise assessment of the effective over-estimation of these diffusivities [3]. Therefore, the magnitude of the over-prediction of strontium release during safety testing might be over-estimated because the discrepancies in strontium retention during irradiation are not captured by the safety testing calculations.

In the end, PARFUME shows a large over-prediction of strontium release during safety testing. However, the magnitude of this over-prediction would increase or decrease depending on whether the experimentally-measured release is from the matrix rather than from the particles, or if strontium is better retained during irradiation than predicted, respectively. In any case, correction factors cannot be derived from the measured data because all three diffusivities in the kernel, $\mathrm{SiC}$, and matrix might be over-estimated, which are too many unknowns to apply the method used for silver and cesium.

\subsection{Krypton Release}

Krypton is unique because it has the $\mathrm{SiC}$ and both PyC layers as diffusion barriers. Krypton release is therefore indicative of the failure of all three coating layers, and is the primary indicator for particle failure during a heating test.

For krypton, there is a limited amount of release data for compacts heated at $1600^{\circ} \mathrm{C}$, partly due to the potential for background contamination from the hot cell contributing to the very low measured krypton activity, and partly because the release fractions were often sufficiently low that released activity was below detection limits. The measured release, including background contamination, was $\leq 5 \times 10^{-6}$ for all $1600^{\circ} \mathrm{C}$ tests, which indicates a low release from intact particles or from particles with failed SiC. Calculated release fractions from compacts containing only intact particles are below $10^{-7}$, i.e., below uranium contamination. In the case of compacts containing one particle with failed SiC, PARFUME predicts release fractions limited to $5 \times 10^{-6}$, which is comparable to the experimental data.

Krypton release from compacts containing particles with failed $\mathrm{SiC}$ tested at 1700 and $1800^{\circ} \mathrm{C}$ was compared with PARFUME predictions. Figure 15 shows the fractional release of krypton for these compacts, and an overprediction by approximately one order of magnitude at $1700^{\circ} \mathrm{C}$, and by up to more than one order of magnitude at $1800^{\circ} \mathrm{C}$. The contribution from intact particles in these compacts was excluded because the release fraction 
from an intact particle is predicted to be around $5 \times 10^{-4}$ at $1700^{\circ} \mathrm{C}$ and about 3 to $4 \%$ at $1800^{\circ} \mathrm{C}$, i.e., considerably larger than the experimental release fractions shown in Figure 15.

To be consistent with PIE observations, the particles with failed SiC layers are also modeled with failed IPyC layers, but intact OPyC layers. Therefore, the over-prediction of the krypton release from compacts containing particles with failed $\mathrm{SiC}$ can be attributed to an over-estimation of the diffusivity of krypton in the kernel or in OPyC, or a combination of both. The presence of multiple efficient barriers to krypton diffusion in the TRISO particle makes the analysis of the potential over-estimation of the diffusivities especially tricky. However, Compact 4-3-2 offers the opportunity to study a clear full particle failure at the beginning of its $1800^{\circ} \mathrm{C}$ test. As detailed in Ref. [18], two particles in Compact 4-3-2 are assumed to have experienced full failures, i.e., consecutive failures of their IPyC, $\mathrm{SiC}$, and $\mathrm{OPyC}$ layers. However, the fission product releases suggest that these particles first experienced $\mathrm{SiC}$ failure (presumed to include IPyC failure as well), followed some time later by failure of the OPyC layer [18]. PARFUME was used to model the first of these two full failures. The successive failures of the layers allows the diffusivity of krypton in PyC to be assessed during the short period when the OPyC layer is the only intact layer left in that particle and, therefore, to bring a partial answer to the overestimation of the IAEA diffusivities.

The computation of the release from Compact 4-3-2 requires combining the results of the releases from the intact particles in the compact to the release of the fully failed particle. As mentioned above, the release from intact particles is largely over-predicted by PARFUME. In the case of Compact 4-3-2, the release fraction of krypton from an intact particle of Compact 4-3-2 is predicted to be $0.15 \%$ after 100 hours at $1800^{\circ} \mathrm{C}$, and about $3 \%$ at the end of the safety test, whereas experimental data show a fraction release of about $10^{-6}$ after 100 hours [18]. This over-prediction can be attributed to an over-estimation of the diffusivity in the kernel, PyC and/or SiC layers used in modeling. In any case, the specific modeling of the full TRISO failure with PARFUME includes only this specific particle (i.e., it does not include any contribution from intact particles); furthermore, it assumes that the fully-failed particle does not release any krypton before the $\mathrm{SiC}$ layer fails.

It is assumed that the IPyC and SiC layers fail simultaneously, with the OPyC layer remaining intact for some time until its eventual failure. This assumption is based on extensive analysis of AGR-1 particles that experienced $\mathrm{SiC}$ failure during safety testing [16]. It is also assumed that the $\mathrm{SiC}$ failure occurs between 143 and 167 hours into the safety test, which corresponds to the time window of the first observed cesium release [18]. The OPyC failure is estimated by the timing of krypton release, which occurs at $246 \mathrm{~h}$. The modeling assumed simultaneous IPyC and $\mathrm{SiC}$ failures at $155 \mathrm{~h}$, in the middle of the range implied by the cesium release data, and OPyC failure at 246h. The IAEA database indicates that the diffusivity of krypton in the kernel is two to three orders of magnitude higher than in PyC, so it is assumed that the release of krypton between $155 \mathrm{~h}$ and $246 \mathrm{~h}$ is driven by diffusion in OPyC. With these assumptions, the over-prediction of the release from intact particles is assumed, a priori, to be caused by an over-estimation of the diffusivity in the SiC layer, rather than in the kernel or PyC layers.

Figure 16 shows the comparison of the experimental fractional release of krypton from Compact 4-3-2 and the predicted fractional release of the single particle experiencing full coating failure in the window 150-260 hours. PARFUME shows a slowly increasing release between the IPyC and SiC failures $(\sim 155 \mathrm{~h})$ and OPyC failure $(\sim 245 \mathrm{~h})$, which corresponds to diffusion through the intact OPyC, as failed layers are assumed to release instantaneously and the diffusivity of krypton in the kernel is more than two orders of magnitude higher than the diffusivity in $\mathrm{OPyC}$ at $1800^{\circ} \mathrm{C}$. The calculated release rate of $2.4 \times 10^{-7} \mathrm{~h}^{-1}$ is in reasonable agreement with the rate of $1.7 \times 10^{-7} \mathrm{~h}^{-1}$ derived from experimental data. PARFUME calculations show that a rate of $1.7 \times 10^{-7} \mathrm{~h}^{-1}$ is achieved by reducing the diffusivity of krypton in PyC by about $20 \%$. This assumes that the over-prediction of the release rate is attributed to an over-estimation of the diffusivity of krypton in OPyC only. In theory, it could also be partly attributed to an over-estimation of the diffusivity in the kernel. However, reducing the diffusivity in the kernel to match the experimental release rate does not lead to the proper integral release fraction, even when a combination of corrections (reduction of the diffusivity of krypton in both the kernel and PyC) is used to match the experimental release rate. This could indicate that the diffusivity of krypton in the kernel is appropriately modeled.

Therefore, as a first approximation, it is more likely that the slight discrepancy between PARFUME and experimental measurements is caused by an over-estimation of the diffusivity in the OPyC layer. The relatively small correction of $\sim 20 \%$ confirms the reasonable agreement between measurements and modeling predictions as it pertains to explaining the release of krypton between $\sim 175 \mathrm{~h}$ and $\sim 245 \mathrm{~h}$ by diffusion through the intact OPyC layer. It also justifies a posteriori that the over-predicted krypton release from intact particles could be attributed 
to an over-estimation of the diffusivity of krypton in the SiC layer, and not in the PyC layers. Because of its much higher predicted diffusivity, the diffusion in the kernel is not the limiting factor, which does not ensure that it is correctly modeled but calculations show that the large correction required to match the release rate of krypton between the $\mathrm{SiC}$ and the $\mathrm{OPyC}$ failures leads to an under-prediction of the total release of the fully failed particle. The stepwise increase in released krypton that occurs at $\sim 168 \mathrm{~h}$ in the experimental data is not fully understood at this time, and is not duplicated by the PARFUME prediction. It is possible that additional mechanisms occur when krypton is first released from the compact that are not included in the PARFUME model.

Even though a decrease of $20 \%$ of the diffusivity of krypton in PyC allows a match between the calculated and measured release rates through OPyC in Compact 4-3-2, it is not enough to explain the discrepancy between PARFUME and experimental release fractions for the other compacts (see Figure 15). This could be partially explained by the modeling assumption that the coating layers fail at the start of the safety tests, which leads to an over-prediction of the total krypton release, but the timing of the failures is not sufficient in itself to explain it (see Section 4.5).

Although a specific analysis of a full TRISO failure in Compact 4-3-2 gives useful hints about the diffusivities in the kernel and $\mathrm{PyC}$ layers at $1800^{\circ} \mathrm{C}$, the complexity of its release due to multiple retention barriers do not lead to a definite conclusion about potential correction factors for the diffusivities in the kernel and the successive coating layers at all safety test temperatures.

\subsection{Impact of the Time of Failure on Fission Product Release}

As mentioned in Section 3.3, the failures of the coating layers are assumed in the model to occur at the beginning of the heating phase. This potentially leads to an over-prediction of fission product release from particles with failed $\mathrm{SiC}$ when the experiment indicates a delay in the onset of $\mathrm{SiC}$ failures.

Table 7 shows the impact of the time of failure of the SiC layer on the calculated release fraction at the end of the safety test for a particle with failed IPyC and SiC layers in Compacts 6-4-1, 3-3-1, and 3-2-3, heated at 1600, 1700 , and $1800^{\circ} \mathrm{C}$, respectively. Times of failure of $0,100,200$, and 300 hours are assumed.

In the case of silver, the release is almost instantaneous once the $\mathrm{SiC}$ layer has failed and the timing of the failure does not impact the magnitude of silver fractional release. Furthermore, the overall silver release is largely dominated by the release from intact particles. In the case of cesium, the release fraction slightly decreases with later times of $\mathrm{SiC}$ failure because the $\mathrm{OPyC}$ is a bit more retentive than for silver. Nevertheless, the maximum drop of $\sim 30 \%$ (at $1600^{\circ} \mathrm{C}$ ) cannot fully explain the discrepancies observed between PARFUME and experimental data in Figure 7.

Similar to the behavior of silver, the overall release of strontium is dominated by the release from intact particles. The limited decrease in strontium release with later $\mathrm{SiC}$ failure times $\left(\sim 6 \%\right.$ maximum at $\left.1600^{\circ} \mathrm{C}\right)$ is, therefore, unnoticeable on the integral fractional release. Finally, the time of failure of the SiC layer mostly impacts the release of krypton if it occurs late during the safety test, so that krypton does not have time to diffuse through the still-retentive OPyC layer. Nevertheless, the relative decrease of krypton release from a particle with failed $\mathrm{SiC}$ remains limited and it cannot explain the discrepancies observed between PARFUME and experimental data in Figure 15.

\section{CONCLUSION}

The PARFUME modeling code was used to predict fission product release from fifteen TRISO-coated fuel compacts during AGR-1 safety tests at 1600,1700 , and $1800^{\circ} \mathrm{C}$. Predictions were then compared to experimental data. Comparisons were made for both compacts containing only intact particles and compacts containing particles with failed IPyC and SiC layers.

The predictions showed different trends in the comparison to experimental measurements depending on the fission product species, which leads to different conclusions regarding the diffusivities used in the modeling of fission product transport:

- Silver

(a) Comparisons between PARFUME and experimental data are made on so-called "matrix-corrected release fractions", which are an attempt at correcting the calculated and experimental release fractions from the contribution from silver left in the matrix or OPyC at the end of irradiation. 
(b) Comparisons between PARFUME and experimental data show an over-prediction of the release from compacts containing only intact particles by up to more than three orders of magnitude.

(c) Comparisons show an over-prediction of the release from compacts containing particles with failed $\mathrm{SiC}$ by up to more than two orders of magnitude.

(d) The diffusivity of silver in $\mathrm{SiC}$ appears to be over-estimated by factors of around 1,000 at 1600 and $1700^{\circ} \mathrm{C}$, and 100 at $1800^{\circ} \mathrm{C}$. Specifically, correction factors to this diffusivity range from $2 \times 10^{-4}$ to $4 \times 10^{-3}$ at $1600^{\circ} \mathrm{C}$, from $8 \times 10^{-4}$ to $2 \times 10^{-3}$ at $1700^{\circ} \mathrm{C}$, and from $2 \times 10^{-3}$ to $4 \times 10^{-2}$ at $1800^{\circ} \mathrm{C}$.

(e) Over-estimation of the diffusivity of silver in UCO might also contribute to the observed differences between experiment and calculation, but it is not possible to determine the magnitude of the effect with the available data.

(f) Silver matrix retention is higher than expected though it is not clear whether this is due to an over-estimation of the silver diffusivity in the matrix or to sorption/desorption effects at the surface of the compacts.

- Cesium

(a) Comparisons between PARFUME and experimental data are made matrix-corrected release fractions.

(b) Comparisons between PARFUME and experimental data show an over-prediction of the release from compacts containing only intact particles by more than three orders of magnitude.

(c) Comparisons show a relatively good agreement in the release from compacts containing particles with failed $\mathrm{SiC}$ with an over-prediction of the release fractions by a factor of about three at most, if the contribution from intact particles in the compact is excluded.

(d) After applying irradiation correction factors to PARFUME calculations, the over-estimation of the diffusivity of cesium in UCO was assessed. The resulting correction factors to the diffusivity of cesium in UCO range from $4 \times 10^{-3}$ to $4 \times 10^{-2}$ at $1600^{\circ} \mathrm{C}$, from $1 \times 10^{-4}$ to $7 \times 10^{-4}$ at $1700^{\circ} \mathrm{C}$, and from $1 \times 10^{-3}$ to $3 \times 10^{-3}$ at $1800^{\circ} \mathrm{C}$. The initial diffusivity used in PARFUME is specific to $\mathrm{UO}_{2}$ but is used for UCO as well due to lack of data for UCO kernels.

(e) The diffusivity of cesium in $\mathrm{SiC}$ is over-estimated. Correction factors to this diffusivity were assessed at $1600^{\circ} \mathrm{C}$ and range from $5 \times 10^{-3}$ to $6 \times 10^{-2}$. No correction factors could be derived at 1700 and $1800^{\circ} \mathrm{C}$.

\section{- $\quad$ Strontium}

(a) There is evidence suggesting that the measured release is predominantly from strontium present outside the $\mathrm{SiC}$ at the end of irradiation rather than from strontium released by particles during the safety tests.

(b) Comparisons between PARFUME and experimental data show an over-prediction of the release from compacts containing only intact particles by up to more than three orders of magnitude.

(c) Comparisons show an over-prediction of the release from compacts containing particles with failed $\mathrm{SiC}$ by about two orders of magnitude.

(d) The over-predictions of the release from particles with failed SiC might be even larger if the measured strontium is from the matrix and not the particles.

(e) Correction factors for the diffusivities cannot be derived from the measured data because there are too many diffusivities (kernel, $\mathrm{SiC}$, matrix) to correct.

- Krypton

(a) Experimental release fractions were less than $5 \times 10^{-6}$ for all compacts heated at $1600^{\circ} \mathrm{C}$, which corresponds to a combination of background contamination and measurement detection limit. PARFUME predicts a fractional release less than $10^{-7}$ (below the level of uranium contamination) for compacts containing only intact particles, and less than $5 \times 10^{-6}$ for compacts containing one particle with failed SiC. In both cases, there is a fairly good agreement on the very low krypton release at $1600^{\circ} \mathrm{C}$.

(b) At 1700 and $1800^{\circ} \mathrm{C}$, comparisons show an over-prediction of the release from compacts containing particles with failed $\mathrm{SiC}$ by up to more than one order of magnitude, respectively, when the calculated contribution from intact particles is removed. PARFUME also largely over-predicts the release fraction from intact particles at these temperatures.

(c) Specific analysis of a full TRISO failure in Compact 4-3-2 shows that the diffusivity in PyC might be overestimated by $\sim 20 \%$ at $1800^{\circ} \mathrm{C}$, while the diffusivity in the kernel appears to be appropriately modeled.

(d) There are not sufficient data from these heating tests to determine which of the TRISO-coating's layers diffusivities are under or over-estimated at all safety test temperatures.

In addition, it was shown that the timing of the failure of the $\mathrm{SiC}$ layer has a negligible impact on the calculated release of all analyzed fission product species but krypton, mostly a result of the near-instantaneous release once the $\mathrm{SiC}$ is breached, or because the decreased release from particles with failed $\mathrm{SiC}$ is unnoticeable when the overall release is dominated by the release from intact particles. In the case of krypton, the timing of the $\mathrm{SiC}$ failure impacts the fractional release because of the assumed simultaneous failure of the IPyC, but the decreased release from particles with failed IPyC and $\mathrm{SiC}$ is not large enough to account for the discrepancies between PARFUME predictions and experimental results. 
Correction factors could only be assessed for silver diffusivities ( $\mathrm{SiC}$ at all safety test temperatures) and cesium diffusivities (kernel at all safety test temperatures and $\mathrm{SiC}$ at $1600^{\circ} \mathrm{C}$ ), and results vary from compact to compact at a given safety test temperature. For strontium, difficulties inherent to the modeling of the release during irradiation or the retention in the matrix made it impossible to derive correction factors. In the case of krypton, all coating layers are retentive, giving too many unknowns for the amount of available experimental data. The integral release nature of the data makes it difficult to draw any conclusion about diffusivities in the kernel and each coating layer of a TRISO particle.

Nevertheless, the important conclusion of these comparisons between PARFUME predictions and experimental results is the far smaller release of fission products at temperature of $1600^{\circ} \mathrm{C}$ and above than expected from calculations using IAEA diffusivities coupled with a Fickian diffusion model. Although it is challenging to determine correct diffusivities, these comparisons show the great fission product retention power of the AGR-1 TRISO fuel under accident conditions. Additionally, these comparisons highlight the limitations of the modeling using a simplified approach based on Fickian diffusion. Complex physico-chemical mechanisms are at play in the transport of fission products that are not easily captured by effective diffusion coefficients in the frame of Fickian diffusion.

\section{ACKNOWLEDGMENTS}

This work was supported by the U.S. Department of Energy, Office of Nuclear Energy, under Department of Energy Idaho Operations Office Contract DE-AC07-05ID14517.

\section{REFERENCES}

[1] R. N. Morris, P. A. Demkowicz, J. D. Hunn, C. A. Baldwin, E. L. Reber, "Performance of AGR-1 high temperature reactor fuel during post-irradiation heating tests", HTR2014-31135, Proceedings of the HTR2014 Conference, Weihai, China, October 27-31, 2014.

[2] P. A. Demkowicz, J. D. Hunn, R. N. Morris, I. J. van Rooyen, T. J. Gerczak, J. M. Harp, S. A. Ploger. “AGR1 Post Irradiation Examination Final Report”, INL/EXT-15-36407, Idaho National Laboratory, August 2015.

[3] B. P. Collin, D. A. Petti, P. A. Demkowicz, J. T. Maki, "Comparison of silver, cesium, and strontium release predictions using PARFUME with results from the AGR-1 irradiation experiment", Journal of Nuclear Materials 466 (2015) 426-442.

[4] G. K. Miller, D. A. Petti, J. T. Maki, D. L. Knudson, "PARFUME Theory and Model Basis Report", INL/EXT-08-14497, Idaho National Laboratory (INL), September 2009.

[5] J. W. Sterbentz, J. M. Harp, P. A. Demkowicz, G. L. Hawkes, G. S. Chang, "Validation of the Physics Analysis used to Characterize the AGR-1 TRISO Fuel Irradiation Test", Paper 15497, Proceedings of ICAPP 2015, Nice, France, May 3-6, 2015.

[6] J. Simonds, "Technical Program Plan for the Very High Temperature Reactor Technology Development Office/Advanced Gas Reactor Fuel Development and Qualification Program”, PLN-3636, Rev. 3, Idaho National Laboratory (INL), May 2014.

[7] B. P. Collin, "AGR-1 Irradiation Test Final As-Run Report”, INL/EXT-10-18097, Rev. 3, Idaho National Laboratory (INL), January 2015.

[8] C. A. Baldwin, J. D. Hunn, R. N. Morris, F. C. Montgomery, C. M. Silva, P. A. Demkowicz, "First elevatedtemperature performance testing of coated particle fuel compacts from the AGR-1 irradiation experiment", Nuclear Engineering and Design, 271 (2014) 131-141.

[9] P. A. Demkowicz, D. V. Laug, D. M. Scates, E. L. Reber, L. G. Roybal, J. B. Walter, J. M. Harp, R. N. Morris, "The Fuel Accident Condition Simulator (FACS) furnace system for high temperature performance testing of VHTR fuel”, Nuclear Engineering and Design, 251 (2012) 164-172.

[10] J. T. Maki, “AGR-1 Irradiation Experiment Test Plan”, INL/EXT-05-00593, Rev. 3, Idaho National Laboratory (INL), October 2009.

[11] G. L. Hawkes, J.W. Sterbentz, J. Maki, B. Pham, "Daily Thermal Predictions of the AGR-1 Experiment With Gas Gaps Varying With Time”, Paper 12111, Proceedings of ICAPP 2012, Chicago, IL, June 24-28, 2012.

[12] J. W. Sterbentz, "JMOCUP As-Run Daily Depletion Calculation for the AGR-1 Experiment in ATR B-10 position”, ECAR-958, Rev. 1, Idaho National Laboratory (INL), August 2011

[13] CEGA Corporation, "NP-MHTGR Material Models of Pyrocarbon and Pyrolytic Silicon Carbide", CEGA002820, Rev. 1, July 1993.

[14] IAEA, "Fuel performance and fission product behaviour in gas cooled reactors", TECDOC-978, November 1997. 
[15] K. Verfondern, “TRISO Fuel Performance Modeling and Simulation”, Comprehensive Nuclear Materials, Vol. 3 (2012) 755-788.

[16] J. D. Hunn, C. A. Baldwin, T. J. Gerczak, F. C. Montgomery, R. N. Morris, C. M. Silva, P. A. Demkowicz, J. M. Harp, S. A. Ploger, "Detection and analysis of particles with breached SiC in AGR-1 fuel compacts", HTR2014-31254, Proceedings of the HTR2014 Conference, Weihai, China, October 27-31, 2014.

[17]P. A. Demkowicz, J. D. Hunn, S. A. Ploger, R. N. Morris, C. A. Baldwin, J. M. Harp, P. L. Winston, T. J. Gerczak, I. J. van Rooyen, F. C. Montgomery, C. M. Silva, "Irradiation performance of AGR-1 high temperature reactor fuel", Nuclear Engineering and Design (2015) http://dx.doi.org/10.1016/j.nucengdes.2015.09.011

[18] P. A. Demkowicz, E. L. Reber, D. M. Scates, L. Scott, B. P. Collin, "First high temperature safety tests of AGR-1 TRISO fuel with the Fuel Accident Condition Simulator (FACS) furnace", Journal of Nuclear Materials 464 (2015) 320-330.

[19]E. Bevillon, R. Ducher, M. Barrachin, R. Dubourg, "Investigation of the diffusion of atomic fission products in UC by density functional calculations", Journal of Nuclear Materials 434 (2013) 240-247. 


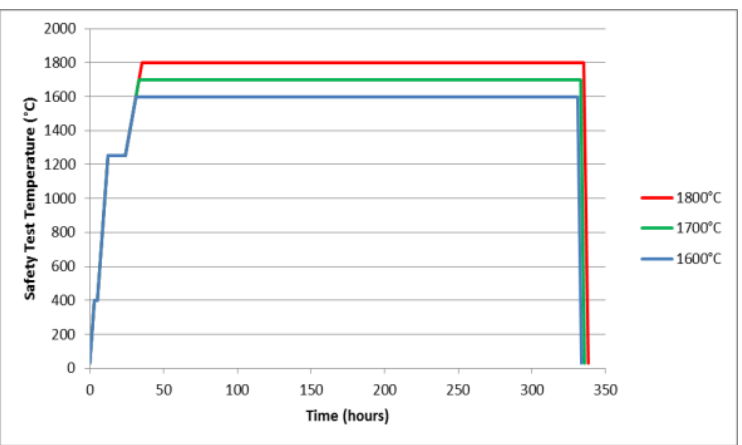

Figure 1: AGR-1 safety test heating plans.

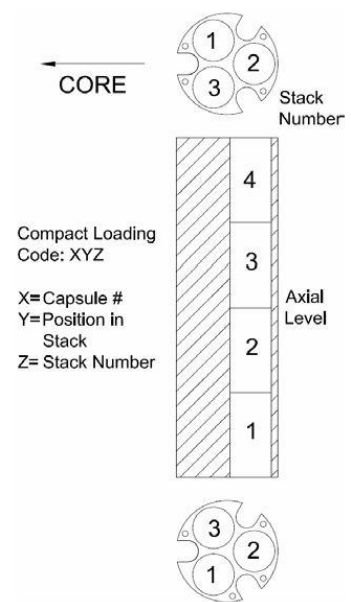

Figure 2: Layout of an AGR-1 capsule. The cross-section view at the top of the figure shows the orientation of the three fuel stacks within the graphite holder and the axial cutaway shows the four axial levels.

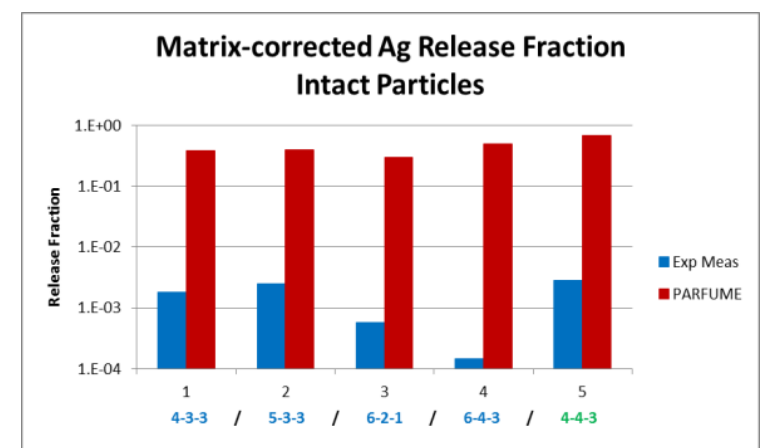

Figure 3: Silver fractional release from compacts containing only intact particles corrected to only include release after the first 24 hours spent at the safety test temperature. PARFUME predictions exclude any silver left outside the $\mathrm{SiC}$ at the end of irradiation. ${ }^{2}$

\footnotetext{
${ }^{2}$ Compact ID color code: compacts safety tested at $1600^{\circ} \mathrm{C}$ appear in blue, green for $1700^{\circ} \mathrm{C}$, and red for $1800^{\circ} \mathrm{C}$.
} 


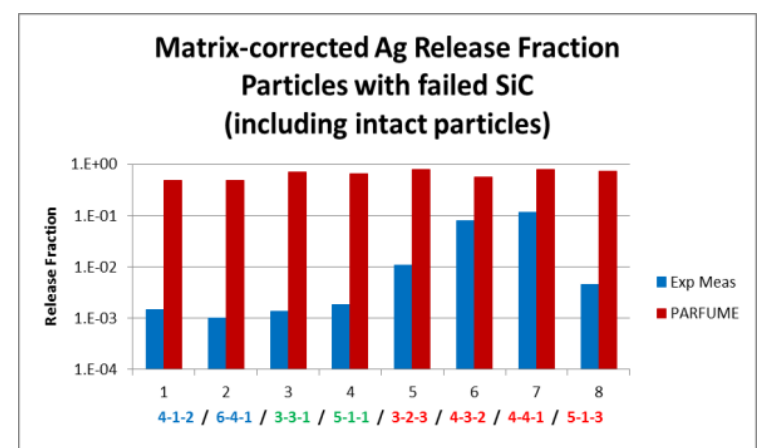

Figure 4: Silver fractional release from compacts containing particles with failed SiC layers corrected to only include release after the first 24 hours spent at the safety test temperature. PARFUME predictions include the release from intact particles and exclude any silver left outside the $\mathrm{SiC}$ at the end of irradiation.
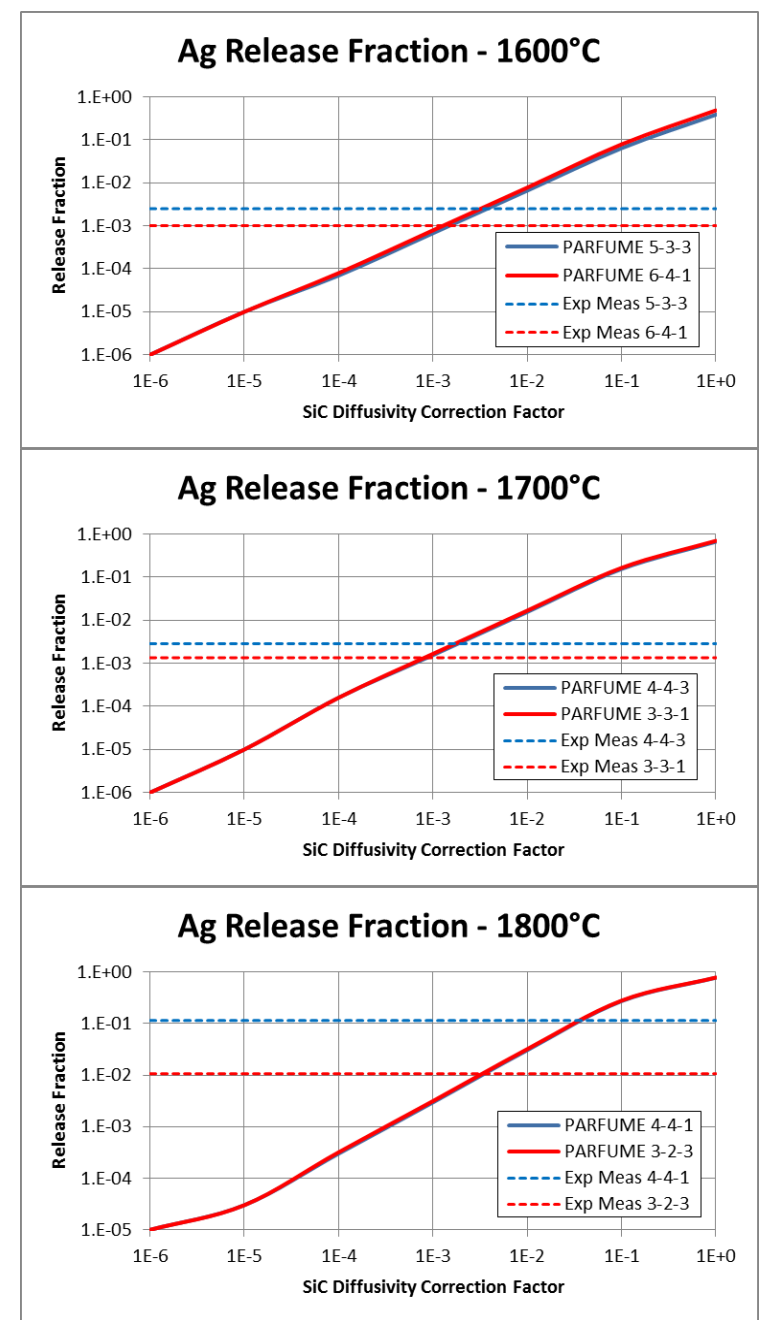

Figure 5: Calculated silver release fraction versus $\mathrm{SiC}$ diffusivity correction factor during safety testing for select compacts at 1600,1700 , and $1800^{\circ} \mathrm{C}$. PARFUME predictions exclude any silver left outside the $\mathrm{SiC}$ at the end of irradiation. Dashed lines represent the experimentally-measured matrix-corrected release fraction for each compact. 


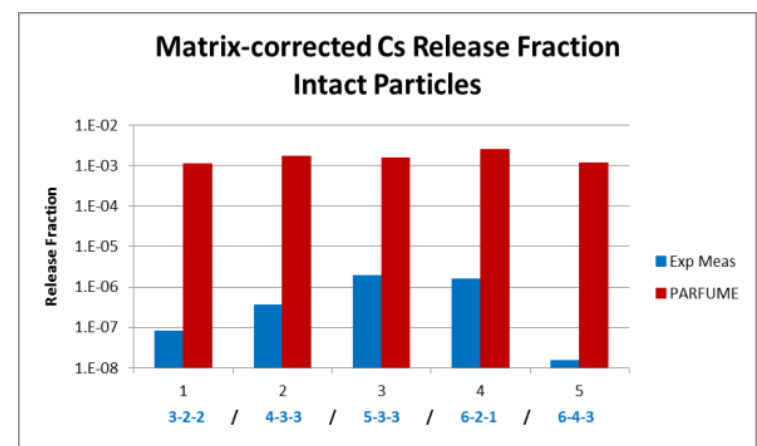

Figure 6: Cesium fractional release from compacts containing only intact particles (all safety tested at $1600^{\circ} \mathrm{C}$ ) corrected to only include release after the first 24 hours spent at the safety test temperature. The diffusivities in the kernel and SiC during irradiation were corrected by factors of $1.25 \times 10^{-2}$ and 0.6 , respectively.

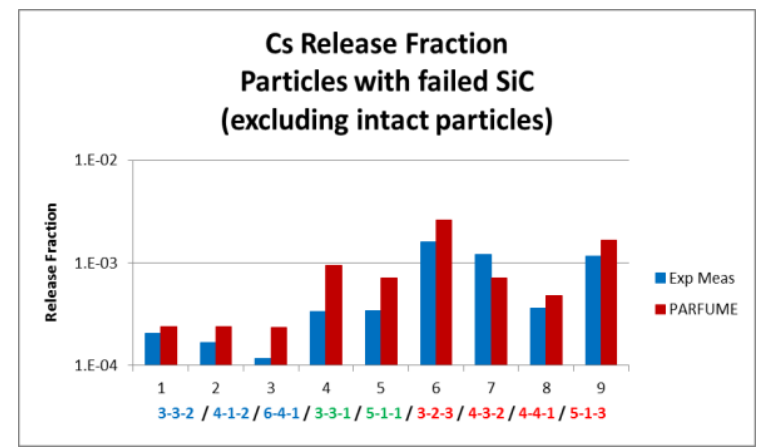

Figure 7: Cesium fractional release from compacts containing particles with failed SiC layers. PARFUME predictions exclude the release from intact particles. The diffusivities in the kernel and SiC during irradiation were corrected by factors of $1.25 \times 10^{-2}$ and 0.6 , respectively.

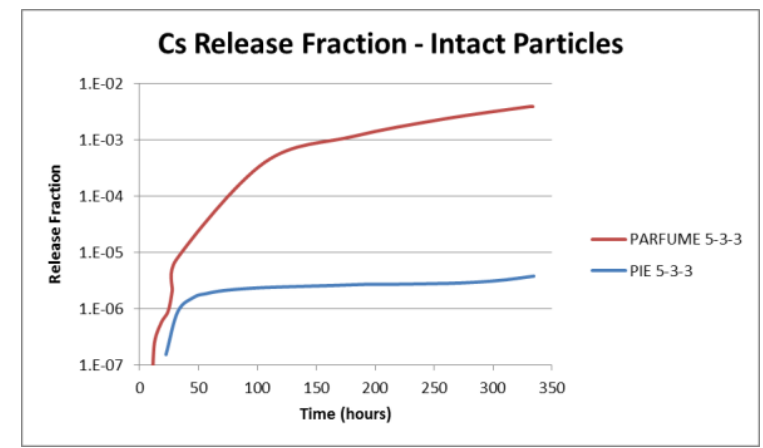

Figure 8: Calculated and experimental cesium fractional releases from Compact 5-3-3 safety tested at $1600^{\circ} \mathrm{C}$ and containing only intact particles as a function of time. The diffusivities in the kernel and SiC during irradiation were corrected by factors of $1.25 \times 10^{-2}$ and 0.6 , respectively.

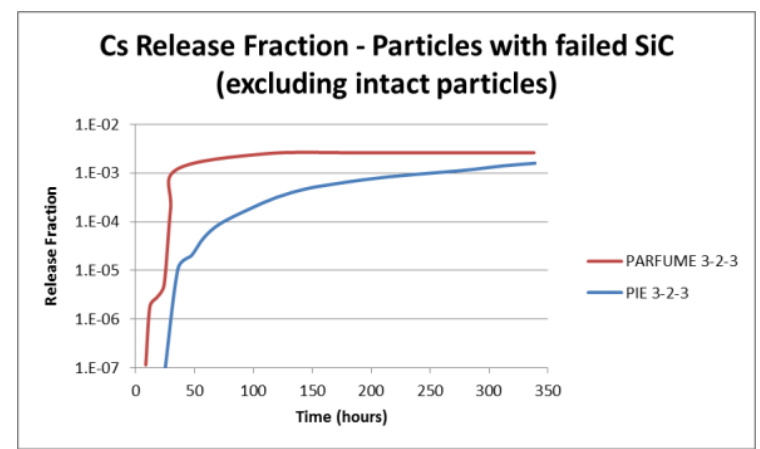

Figure 9: Calculated and experimental cesium fractional releases from Compact 3-2-3 safety tested at $1800^{\circ} \mathrm{C}$ and containing eleven particles with failed SiC layers as a function of time. PARFUME predictions exclude the release from intact particles. The diffusivities in the kernel and SiC during irradiation were corrected by factors of $1.25 \times 10^{-2}$ and 0.6 , respectively. 


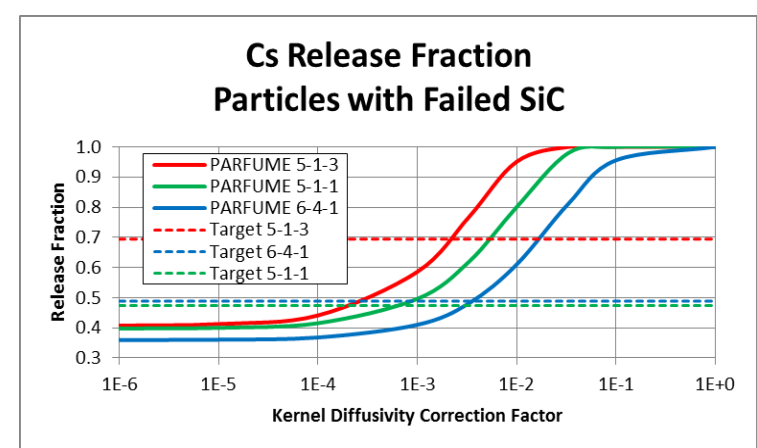

Figure 10: Calculated cesium release fraction versus kernel diffusivity correction factor during safety testing for a particle with failed $\mathrm{SiC}$ at $1600^{\circ} \mathrm{C}$ (Compact 6-4-1), $1700^{\circ} \mathrm{C}$ (Compact 5-1-1), and $1800^{\circ} \mathrm{C}$ (Compact 5-1-3). Dashed lines show the calculated release fractions that the particles with failed $\mathrm{SiC}$ should have to produce the observed experimental release in each compact. The diffusivities in the kernel and SiC during irradiation were corrected by factors of $1.25 \times 10^{-2}$ and 0.6 , respectively.

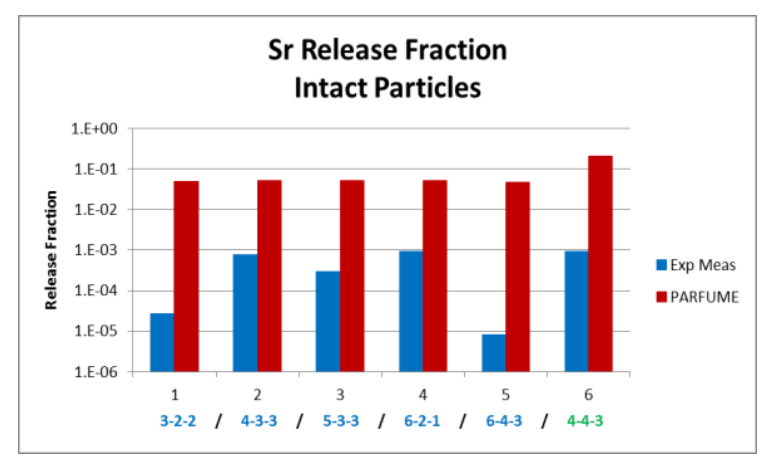

Figure 11: Strontium fractional release from compacts containing only intact particles.

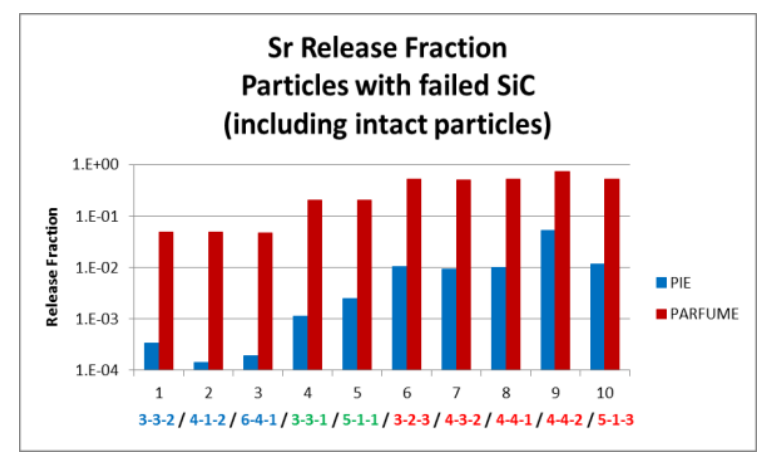

Figure 12: Strontium fractional release from compacts containing particles with failed SiC layers. PARFUME predictions include the release from intact particles.

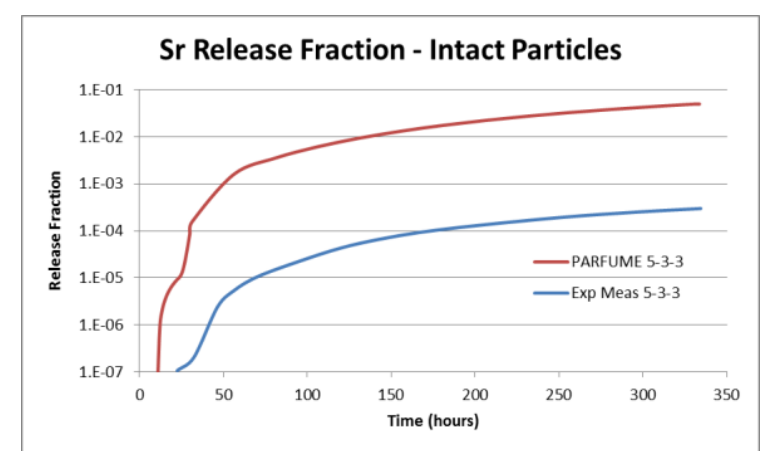

Figure 13: Calculated and experimental strontium fractional releases as a function of time from compacts containing only intact particles. 


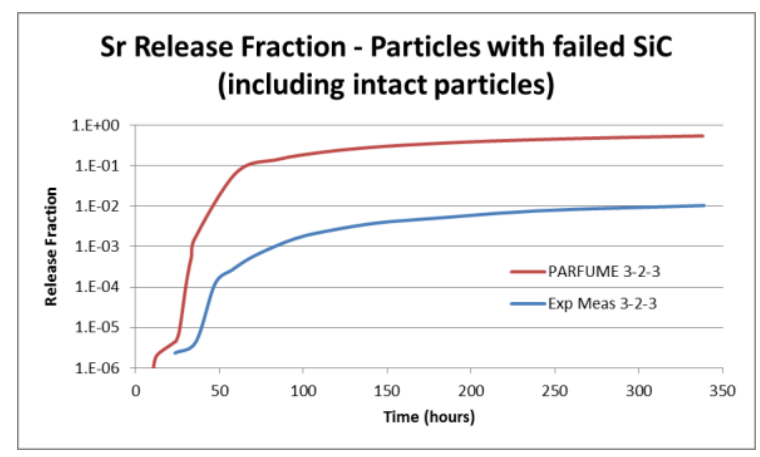

Figure 14: Calculated and experimental strontium fractional releases as a function of time from compacts containing particles with failed SiC layers. PARFUME predictions include the release from intact particles.

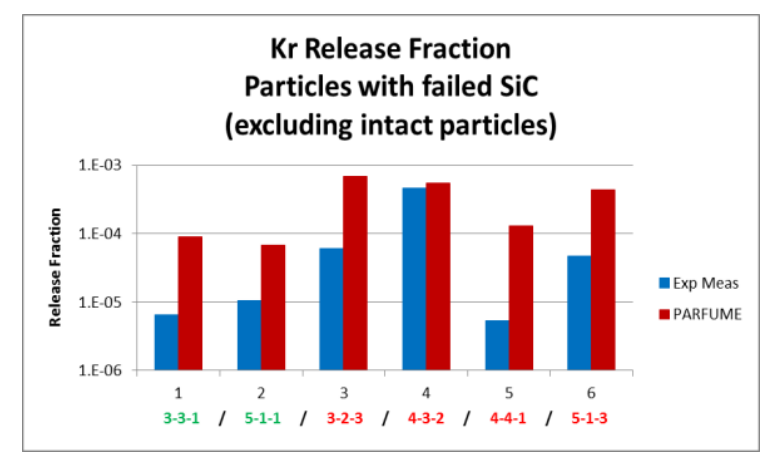

Figure 15: Krypton fractional release from compacts containing particles with failed SiC layers. PARFUME predictions exclude the release from intact particles.

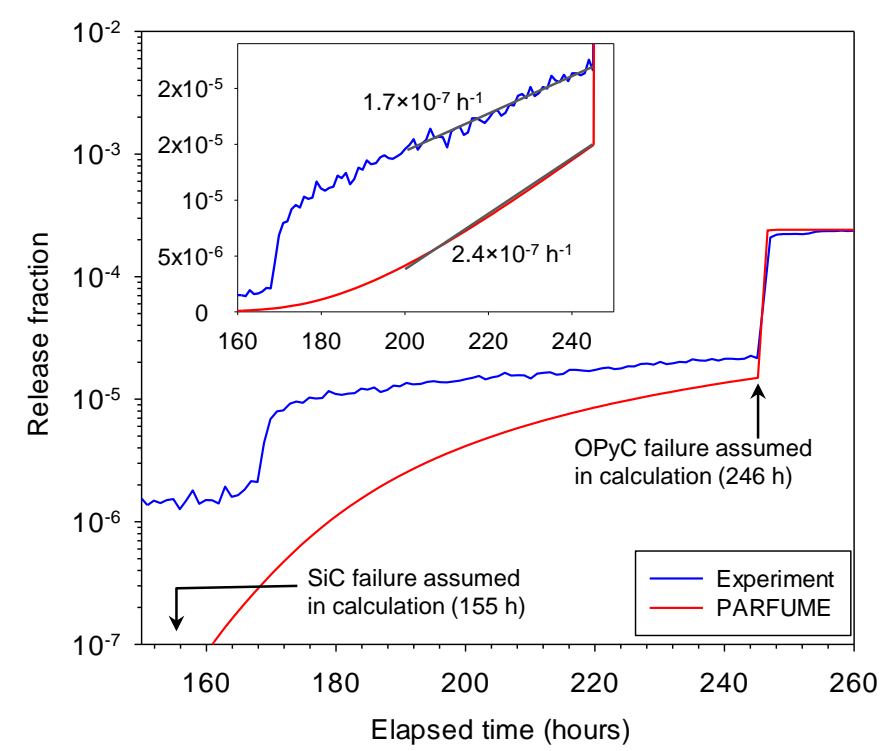

Figure 16: Comparison of experimental data and PARFUME prediction of krypton release from Compact 4-3-2 during the $1800^{\circ} \mathrm{C}$ test. Inset shows a portion of the two curves on a linear scale and the corresponding release rates between 160 and 250 hours. 
Table 1: Compacts used for safety testing.

\begin{tabular}{|c|c|c|c|}
\hline Compact & $\begin{array}{c}\text { Burnup } \\
(\mathbf{\%} \text { FIMA })\end{array}$ & $\begin{array}{c}\text { Fast Fluence } \\
\left(\times \mathbf{1 0}^{\mathbf{2 5}} \mathbf{n} \mathbf{m}^{\mathbf{2}},\right. \\
\mathbf{E}>\mathbf{0 . 1 8} \mathbf{~ M e V})\end{array}$ & $\begin{array}{c}\text { Safety Test } \\
\text { Temperature } \\
\left({ }^{\circ} \mathbf{C}\right)\end{array}$ \\
\hline $\mathbf{3 - 2 - 2}$ & 17.02 & 3.79 & 1600 \\
\hline $\mathbf{3 - 3 - 2}$ & 17.02 & 3.80 & 1600 \\
\hline $\mathbf{4 - 1 - 2}$ & 17.39 & 3.72 & 1600 \\
\hline $\mathbf{4 - 3 - 3}$ & 18.63 & 4.16 & 1600 \\
\hline $\mathbf{5 - 3 - 3}$ & 17.01 & 3.65 & 1600 \\
\hline $\mathbf{6 - 2 - 1}$ & 14.20 & 2.87 & 1600 \\
\hline $\mathbf{6 - 4 - 1}$ & 13.35 & 2.43 & 1600 \\
\hline $\mathbf{6 - 4 - 3}$ & 13.35 & 2.46 & 1600 \\
\hline $\mathbf{3 - 3 - 1}$ & 19.07 & 4.23 & 1700 \\
\hline $\mathbf{4 - 4 - 3}$ & 18.99 & 4.06 & 1700 \\
\hline $\mathbf{5 - 1 - 1}$ & 18.15 & 3.76 & 1700 \\
\hline $\mathbf{3 - 2 - 3}$ & 19.12 & 4.28 & 1800 \\
\hline $\mathbf{4 - 3 - 2}$ & 16.38 & 3.68 & 1800 \\
\hline $\mathbf{4 - 4 - 1}$ & 18.96 & 3.99 & 1800 \\
\hline $\mathbf{5 - 1 - 3}$ & 18.19 & 3.82 & 1800 \\
\hline
\end{tabular}

Table 2: Diffusion coefficients used in PARFUME.

\begin{tabular}{|c|c|c|c|c|c|}
\hline Species & $\begin{array}{c}\mathrm{D}_{0, \mathrm{i}}\left(\mathrm{m}^{2} / \mathrm{s}\right) \\
\mathrm{Q}_{0, \mathrm{i}} \\
(\mathrm{kJ} / \mathrm{mol}) \\
\end{array}$ & $\begin{array}{c}\text { Kernel } \\
\left(\mathbf{U O}_{2}\right)\end{array}$ & PyC & $\mathrm{SiC}$ & $\begin{array}{c}\text { Matrix } \\
\text { graphite }\end{array}$ \\
\hline \multirow{3}{*}{ Ag } & $\mathrm{D}_{0,1}$ & $6.7 \times 10^{-9}$ & $5.3 \times 10^{-9}$ & $3.6 \times 10^{-9}$ & 1.6 \\
\hline & $\mathbf{Q}_{0,1}$ & 165 & 154 & 215 & 258 \\
\hline & $\begin{array}{l}D_{0,2} \\
Q_{0,2}\end{array}$ & - & - & - & - \\
\hline \multirow{3}{*}{ Cs } & $D_{0,1}$ & $5.6 \times 10^{-8}$ & $6.3 \times 10^{-8}$ & $5.5 \times 10^{-14}$ & $3.6 \times 10^{-4}$ \\
\hline & $\mathbf{Q}_{0,1}$ & 209 & 222 & 125 & 189 \\
\hline & $\begin{array}{l}D_{0,2} \\
Q_{0,2}\end{array}$ & $\begin{array}{c}5.2 \times 10^{-4} \\
362\end{array}$ & - & $\begin{array}{c}1.6 \times 10^{-2} \\
514\end{array}$ & - \\
\hline \multirow{3}{*}{$\mathrm{Sr}$} & $D_{0,1}$ & $2.2 \times 10^{-3}$ & $2.3 \times 10^{-6}$ & $1.2 \times 10^{-9}$ & $10^{-2}$ \\
\hline & $\mathbf{Q}_{0,1}$ & 488 & 197 & 205 & 303 \\
\hline & $\begin{array}{l}D_{0,2} \\
Q_{0,2}\end{array}$ & - & - & $\begin{array}{c}1.8 \times 10^{6} \\
791\end{array}$ & - \\
\hline \multirow{3}{*}{$\mathbf{K r}$} & $D_{0,1}$ & $8.8 \times 10^{-15}$ & $2.9 \times 10^{-8}$ & $3.7 \times 10^{1}$ & $6.0 \times 10^{-6}$ \\
\hline & $Q_{0,1}$ & 54 & 291 & 657 & 0 \\
\hline & $\begin{array}{l}D_{0,2} \\
Q_{0,2}\end{array}$ & $\begin{array}{c}6.0 \times 10^{-1} \\
480\end{array}$ & $\begin{array}{c}2.0 \times 10^{5} \\
923\end{array}$ & - & - \\
\hline
\end{tabular}

Notes: $\mathrm{UO}_{2}$ values are used for the kernel due to lack of data for UCO kernels; the buffer has a set diffusivity of $10^{-8} \mathrm{~m}^{2} / \mathrm{s}$; PARFUME does not use the fluence-dependent diffusivity of cesium in SiC; Krypton coefficients for the kernel and $\mathrm{SiC}$ layer are specific to the modeling of fission product transport under accident conditions. 
Table 3: Compacts containing particles with failed SiC [2].

\begin{tabular}{|c|c|c|}
\hline Compact & $\begin{array}{c}\text { Number of particles } \\
\text { with failed IPyC \& SiC }\end{array}$ & $\begin{array}{c}\text { Safety Test } \\
\text { Temperature }\left({ }^{\circ} \mathbf{C}\right)\end{array}$ \\
\hline $\mathbf{3 - 2 - 2}$ & 0 & 1600 \\
\hline $\mathbf{3 - 3 - 2}$ & 1 & 1600 \\
\hline $\mathbf{4 - 1 - 2}$ & 0 & 1600 \\
\hline $\mathbf{4 - 3 - 3}$ & 0 & 1600 \\
\hline $\mathbf{5 - 3 - 3}$ & 0 & 1600 \\
\hline $\mathbf{6 - 2 - 1}$ & 1 & 1600 \\
\hline $\mathbf{6 - 4 - 1}$ & 0 & 1600 \\
\hline $\mathbf{6 - 4 - 3}$ & 4 & 1600 \\
\hline $\mathbf{3 - 3 - 1}$ & 0 & 1700 \\
\hline $\mathbf{4 - 4 - 3}$ & 3 & 1700 \\
\hline $\mathbf{5 - 1 - 1}$ & 11 & 1700 \\
\hline $\mathbf{3 - 2 - 3}$ & $3^{*}$ & 1800 \\
\hline $\mathbf{4 - 3 - 2}$ & 2 & 1800 \\
\hline $\mathbf{4 - 4 - 1}$ & 7 & 1800 \\
\hline $\mathbf{5 - 1 - 3}$ & 0 & 1800 \\
\hline
\end{tabular}

Notes: each compact is uniquely identified in the format X-Y-Z, where $\mathrm{X}$ indicates the capsule, $\mathrm{Y}$ the axial level within the capsule, and $\mathrm{Z}$ the stack (see Figure 2); Compact 4-3-2 is modeled with 2 exposed kernels and 1 particle with failed IPyC and SiC layers at the end of the test.

Table 4: Correction factors to silver diffusivity in $\mathrm{SiC}$ at 1600,1700 , and $1800^{\circ} \mathrm{C}$.

\begin{tabular}{|c|c|c|c|c|c|}
\hline $\begin{array}{l}\text { Compact } \\
\left(1600^{\circ} \mathrm{C}\right)\end{array}$ & $\begin{array}{l}\text { Correction } \\
\text { Factor }\end{array}$ & $\begin{array}{l}\text { Compact } \\
\left(1700^{\circ} \mathrm{C}\right)\end{array}$ & $\begin{array}{l}\text { Correction } \\
\text { Factor }\end{array}$ & $\begin{array}{l}\text { Compact } \\
\left(\mathbf{1 8 0 0}^{\circ} \mathrm{C}\right)\end{array}$ & $\begin{array}{c}\text { Correction } \\
\text { Factor }\end{array}$ \\
\hline $4-1-2$ & $2 \times 10^{-3}$ & 3-3-1 & $8 \times 10^{-4}$ & 3-2-3 & $3 \times 10^{-3}$ \\
\hline 4-3-3 & $3 \times 10^{-3}$ & 4-4-3 & $2 \times 10^{-3}$ & 4-3-2 & $3 \times 10^{-2}$ \\
\hline 5-3-3 & $4 \times 10^{-3}$ & 5-1-1 & $1 \times 10^{-3}$ & 4-4-1 & $4 \times 10^{-2}$ \\
\hline 6-2-1 & $1 \times 10^{-3}$ & & & $5-1-3$ & $2 \times 10^{-3}$ \\
\hline 6-4-1 & $1 \times 10^{-3}$ & & & & \\
\hline 6-4-3 & $2 \times 10^{-4}$ & & & & \\
\hline
\end{tabular}

Table 5: Experimental and PARFUME cesium release fractions (RF) from particles with failed SiC and their host compacts and safety test (ST) correction factors to cesium diffusivity in the kernel at 1600,1700 , and $1800^{\circ} \mathrm{C}$.

\begin{tabular}{|c|c|c|c|c|c|c|}
\hline Compact & $\begin{array}{l}\text { Safety Test } \\
\text { Temperature }\end{array}$ & $\begin{array}{l}\text { Experimental } \\
\text { compact RF }\end{array}$ & $\begin{array}{l}\text { PARFUME } \\
\text { compact RF }\end{array}$ & $\begin{array}{c}\text { Target RF } \\
\text { Particle with } \\
\text { failed SiC }\end{array}$ & $\begin{array}{c}\text { PARFUME } \\
\text { Minimum RF }\end{array}$ & $\begin{array}{c}\text { ST } \\
\text { correction } \\
\text { factor to Cs } \\
\text { diffusivity in } \\
\text { the kernel }\end{array}$ \\
\hline 3-3-2 & $1600^{\circ} \mathrm{C}$ & $2.0 \times 10^{-4}$ & $2.4 \times 10^{-4}$ & $85 \%$ & $36 \%$ & $4 \times 10^{-2}$ \\
\hline $4-1-2$ & $1600^{\circ} \mathrm{C}$ & $1.7 \times 10^{-4}$ & $2.4 \times 10^{-4}$ & $69 \%$ & $40 \%$ & $2 \times 10^{-2}$ \\
\hline $6-4-1$ & $1600^{\circ} \mathrm{C}$ & $1.2 \times 10^{-4}$ & $2.4 \times 10^{-4}$ & $49 \%$ & $36 \%$ & $4 \times 10^{-3}$ \\
\hline 3-3-1 & $1700^{\circ} \mathrm{C}$ & $3.3 \times 10^{-4}$ & $9.5 \times 10^{-4}$ & $35 \%$ & $36 \%$ & $\mathrm{n} / \mathrm{c}$ \\
\hline $5-1-1$ & $1700^{\circ} \mathrm{C}$ & $3.4 \times 10^{-4}$ & $7.2 \times 10^{-4}$ & $47 \%$ & $40 \%$ & $7 \times 10^{-4}$ \\
\hline 3-2-3 & $1800^{\circ} \mathrm{C}$ & $1.6 \times 10^{-3}$ & $2.6 \times 10^{-3}$ & $60 \%$ & $37 \%$ & $1 \times 10^{-3}$ \\
\hline 4-3-2 & $1800^{\circ} \mathrm{C}$ & $1.2 \times 10^{-3}$ & $7.2 \times 10^{-4}$ & $167 \%$ & $49 \%$ & $\mathrm{n} / \mathrm{c}$ \\
\hline 4-4-1 & $1800^{\circ} \mathrm{C}$ & $3.6 \times 10^{-4}$ & $4.8 \times 10^{-4}$ & $75 \%$ & $37 \%$ & $3 \times 10^{-3}$ \\
\hline $5-1-3$ & $1800^{\circ} \mathrm{C}$ & $1.2 \times 10^{-3}$ & $1.7 \times 10^{-3}$ & $69 \%$ & $41 \%$ & $3 \times 10^{-3}$ \\
\hline
\end{tabular}

Notes: the diffusivities in the kernel and SiC during irradiation were corrected by factors of $1.25 \times 10^{-2}$ and 0.6 , respectively; "target release fractions" (column 5) are obtained by dividing the experimental compact release fraction (column 3) by the calculated release fraction (column 4); safety test correction factors cannot be calculated $(\mathrm{n} / \mathrm{c})$ when the PARFUME release fraction (column 4$)$ is smaller than the experimental release fraction during the safety test (column 3), resulting in a target value greater than $100 \%$. 
Table 6: Correction factors to cesium diffusivity in $\mathrm{SiC}$ at $1600^{\circ} \mathrm{C}$ for the compacts containing only intact particles.

\begin{tabular}{|c|c|}
\hline $\begin{array}{c}\text { Compact } \\
\left(\mathbf{1 6 0 0}^{\circ} \mathbf{C}\right)\end{array}$ & $\begin{array}{c}\text { Correction } \\
\text { Factor }\end{array}$ \\
\hline $\mathbf{3 - 2 - 2}$ & $3 \times 10^{-2}$ \\
\hline $\mathbf{4 - 3 - 3}$ & $9 \times 10^{-3}$ \\
\hline $\mathbf{5 - 3 - 3}$ & $6 \times 10^{-2}$ \\
\hline $\mathbf{6 - 2 - 1}$ & $8 \times 10^{-3}$ \\
\hline $\mathbf{6 - 4 - 3}$ & $5 \times 10^{-3}$ \\
\hline
\end{tabular}

Notes: the diffusivities in the kernel and SiC during irradiation were corrected by factors of $1.25 \times 10^{-2}$ and 0.6 , respectively; the safety test correction factor to the diffusivity in the kernel was taken equal to $1.25 \times 10^{-2}$ using best-estimate results from Table 5 .

Table 7: Impact of the time of failure on fractional release for a particle with failed SiC in Compact 6-4-1 $\left(1600^{\circ} \mathrm{C}\right)$, Compact $3-3-1\left(1700^{\circ} \mathrm{C}\right)$, and Compact 3-2-3 $\left(1800^{\circ} \mathrm{C}\right)$.

\begin{tabular}{|c|c|c|c|c|}
\hline \multirow{2}{*}{ Species } & \multicolumn{4}{|c|}{ Compact 6-4-1 $\left(1600^{\circ} \mathrm{C}\right)$} \\
\hline & $\mathbf{0 h}$ & $100 h$ & $200 h$ & 300h \\
\hline Ag & $78 \%$ & $78 \%$ & $78 \%$ & $76 \%$ \\
\hline Cs & $98 \%$ & $98 \%$ & $90 \%$ & $69 \%$ \\
\hline $\mathbf{S r}$ & $13 \%$ & $11 \%$ & $9 \%$ & $7 \%$ \\
\hline \multirow[t]{3}{*}{$\mathbf{K r}$} & $2 \%$ & $2 \%$ & $0.4 \%$ & $0.1 \%$ \\
\hline & \multicolumn{4}{|c|}{ Compact 3-3-1 $\left(1700^{\circ} \mathrm{C}\right)$} \\
\hline & $\mathbf{0 h}$ & $100 \mathrm{~h}$ & $200 h$ & 300h \\
\hline Ag & $84 \%$ & $84 \%$ & $84 \%$ & $84 \%$ \\
\hline Cs & $99 \%$ & $99 \%$ & $96 \%$ & $83 \%$ \\
\hline $\mathbf{S r}$ & $29 \%$ & $29 \%$ & $29 \%$ & $28 \%$ \\
\hline \multirow[t]{3}{*}{$\mathbf{K r}$} & $9 \%$ & $9 \%$ & $3 \%$ & $1 \%$ \\
\hline & \multicolumn{4}{|c|}{ Compact $3-2-3\left(1800^{\circ} \mathrm{C}\right)$} \\
\hline & $\mathbf{0 h}$ & $100 h$ & $200 h$ & 300h \\
\hline Ag & $83 \%$ & $83 \%$ & $83 \%$ & $83 \%$ \\
\hline Cs & $99 \%$ & $99 \%$ & $98 \%$ & $92 \%$ \\
\hline $\mathrm{Sr}$ & $55 \%$ & $55 \%$ & $54 \%$ & $54 \%$ \\
\hline $\mathbf{K r}$ & $26 \%$ & $25 \%$ & $13 \%$ & $7 \%$ \\
\hline
\end{tabular}




\section{Bibliography}

[1] R. N. Morris, P. A. Demkowicz, J. D. Hunn, C. A. Baldwin, E. L. Reber, "Performance of AGR-1 high temperature reactor fuel during post-irradiation heating tests", HTR2014-31135, Proceedings of the HTR2014 Conference, Weihai, China, October 27-31, 2014.

[2] P. A. Demkowicz, J. D. Hunn, R. N. Morris, I. J. van Rooyen, T. J. Gerczak, J. M. Harp, S. A. Ploger. “AGR- 1 Post Irradiation Examination Final Report”, INL/EXT-15-36407, Idaho National Laboratory, August 2015.

[3] B. P. Collin, D. A. Petti, P. A. Demkowicz, J. T. Maki, "Comparison of silver, cesium, and strontium release predictions using PARFUME with results from the AGR-1 irradiation experiment", Journal of Nuclear Materials 466 (2015) 426-442.

[4] G. K. Miller, D. A. Petti, J. T. Maki, D. L. Knudson, "PARFUME Theory and Model Basis Report", INL/EXT-08-14497, Idaho National Laboratory (INL), September 2009.

[5] J. W. Sterbentz, J. M. Harp, P. A. Demkowicz, G. L. Hawkes, G. S. Chang, "Validation of the Physics Analysis used to Characterize the AGR-1 TRISO Fuel Irradiation Test", Paper 15497, Proceedings of ICAPP 2015, Nice, France, May 3-6, 2015.

[6] J. Simonds, "Technical Program Plan for the Very High Temperature Reactor Technology Development Office/Advanced Gas Reactor Fuel Development and Qualification Program", PLN-3636, Rev. 3, Idaho National Laboratory (INL), May 2014.

[7] B. P. Collin, “AGR-1 Irradiation Test Final As-Run Report”, INL/EXT-10-18097, Rev. 3, Idaho National Laboratory (INL), January 2015.

[8] C. A. Baldwin, J. D. Hunn, R. N. Morris, F. C. Montgomery, C. M. Silva, P. A. Demkowicz, "First elevatedtemperature performance testing of coated particle fuel compacts from the AGR-1 irradiation experiment”, Nuclear Engineering and Design, 271 (2014) 131-141.

[9] P. A. Demkowicz, D. V. Laug, D. M. Scates, E. L. Reber, L. G. Roybal, J. B. Walter, J. M. Harp, R. N. Morris, "The Fuel Accident Condition Simulator (FACS) furnace system for high temperature performance testing of VHTR fuel”, Nuclear Engineering and Design, 251 (2012) 164-172.

[10]J. T. Maki, “AGR-1 Irradiation Experiment Test Plan”, INL/EXT-05-00593, Rev. 3, Idaho National Laboratory (INL), October 2009.

[11]G. L. Hawkes, J.W. Sterbentz, J. Maki, B. Pham, "Daily Thermal Predictions of the AGR-1 Experiment With Gas Gaps Varying With Time”, Paper 12111, Proceedings of ICAPP 2012, Chicago, IL, June 24-28, 2012.

[12]J. W. Sterbentz, "JMOCUP As-Run Daily Depletion Calculation for the AGR-1 Experiment in ATR B-10 position”, ECAR-958, Rev. 1, Idaho National Laboratory (INL), August 2011

[13]CEGA Corporation, "NP-MHTGR Material Models of Pyrocarbon and Pyrolytic Silicon Carbide", CEGA- 002820, Rev. 1, July 1993.

[14]IAEA, "Fuel performance and fission product behaviour in gas cooled reactors", TECDOC-978, November 1997. 
[15]K. Verfondern, “TRISO Fuel Performance Modeling and Simulation”, Comprehensive Nuclear Materials, Vol. 3 (2012) 755-788.

[16]J. D. Hunn, C. A. Baldwin, T. J. Gerczak, F. C. Montgomery, R. N. Morris, C. M. Silva, P. A. Demkowicz, J. M. Harp, S. A. Ploger, "Detection and analysis of particles with breached SiC in AGR-1 fuel compacts", HTR2014-31254, Proceedings of the HTR2014 Conference, Weihai, China, October 2731, 2014.

[17]P. A. Demkowicz, J. D. Hunn, R. N. Morris, C. A. Baldwin, J. M. Harp, P. L. Winston, S. A. Ploger, T. J. Gerczak, I. J. van Rooyen, F. C. Montgomery, C. M. Silva, "Irradiation performance of AGR-1 high temperature reactor fuel", HTR2014-31182, Proceedings of the HTR2014 Conference, Weihai, China, October 27-31, 2014.

[18]P. A. Demkowicz, E. L. Reber, D. M. Scates, L. Scott, B. P. Collin, "First high temperature safety tests of AGR-1 TRISO fuel with the Fuel Accident Condition Simulator (FACS) furnace", Journal of Nuclear Materials 464 (2015) 320-330.

[19]E. Bevillon, R. Ducher, M. Barrachin, R. Dubourg, "Investigation of the diffusion of atomic fission products in UC by density functional calculations", Journal of Nuclear Materials 434 (2013) 240-247. 